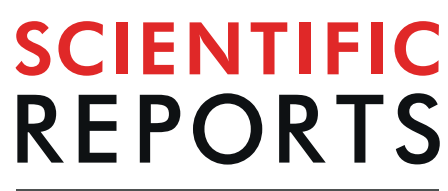

\title{
Cube natural sea salt ameliorates obesity in high fat diet-induced obese mice and 3T3-L1 adipocytes
}

\author{
Eui-Seong Park ${ }^{1}$, TingYu $\mathbb{(}^{2}{ }^{2}$, Kiho Yang $\mathbb{D}^{3}$, Shinil Choi ${ }^{4}$, Seung-Min Lee $\mathbb{C}^{1 *} \&$ \\ Kun-Young Park ${ }^{2 *}$
}

Sodium is an essential component of the human body, with known influences on obesity. This paper reports the effect of cube natural sea salt (CNS) on the reduction of obesity in high fat diet-induced obese C57BL/6 mice and 3T3-L1 adipocytes, by ameliorating the obesity parameters and obesityrelated gene mechanisms. The suppression of high fat diet-induced obesity and differentiated 3T3-L1 adipocytes by sea salt depends on the manufacturing process and mineral content. The manufacturing method using only new sea water (Cube natural sea salt) decreases the magnesium (Mg) and sulfur (S) content in the salt with different crystallization and morphologies, compared to the general manufacturing method (Generally manufactured sea salt, GS). Mg in salt is known to considerably affect obesity; an appropriate concentration of magnesium chloride $\left(\mathrm{MgCl}_{2}\right)$ reduces lipid accumulation significantly and regulates the lipogenesis and liver enzyme activity. Our results indicate that sea salt contains an appropriate level of $\mathrm{Mg}$ as compared to table salt (purified salt, $\mathrm{NaCl}$ ), and is important for regulating obesity, as observed in the in vivo and in vitro anti-obesity effects of CNS. The Mg content and mineral ratio of sea salt are important factors that ameliorate the lipid metabolism and liver enzyme activity in high fat diet induced obesity, and contents of $\mathrm{Mg}$ in sea salt can be altered by modifying the manufacturing process.

Salt is required to maintain homeostasis in the body by regulating the membrane potential, fluid volume, acidbase balance, and nervous system. Globally, many countries predominantly eat purified (iodized), rock, and sea salt. Purified salt ( $99 \%$ sodium chloride, $\mathrm{NaCl}$; generally called table salt) is made from sodium ion $\left(\mathrm{Na}^{+}\right)$and chloride ion $\left(\mathrm{Cl}^{-}\right)$from sea water using an ion exchange membrane electrodialysis process, and is composed of more than $99 \% \mathrm{NaCl}^{1}$. Sea salt (SS) is crystallized from seawater in salt ponds using sunlight and wind ${ }^{2}$. Unlike purified salt, SS generally contains $92.4 \sim 94.4 \% \mathrm{NaCl}$ and various other minerals, such as potassium (K), magnesium $(\mathrm{Mg})$, calcium $(\mathrm{Ca})$, and sulfur $(\mathrm{S})^{3}$. This imparts numerous health functionalities to $\mathrm{SS}^{4-9}$ and a unique taste $^{10}$ as compared to purified salt. In addition, our previous study showed that the crystallization time and evaporating method of seawater are important factors affecting the quality, mineral composition, taste, and health functions of SS.

High salt consumption has synergistic effects in western diet-induced metabolic diseases ${ }^{11}$. In Europe and Northern America, most people eat processed foods (added high salt content using purified salt) compared to home cooked foods (as high as 75\% in USA and UK) ${ }^{12}$. Moreover, high-income English-speaking countries have the highest rate of obesity in the world ${ }^{13}$. In addition, beverage consumption has increased the obesity risk ${ }^{14,15}$ because of their salt (purified salt) and sucrose content. Overall, one possible reason for obesity is the high intake level of purified salt ${ }^{16}$, which is cheaper than naturally manufactured salt. Therefore, most manufactured beverages and foods include purified salt, and most people unwittingly add purified salt to their diet. Dietary foods (purified salt consumption) are associated with the incidence of obesity, and purified salt intake has also been reported to increase the incidence of obesity compared to naturally manufactured salt ${ }^{7}$. It has previously been reported that SS can help to prevent obesity in high fat diet-induced obese mice, indicating that the consumption of SS may help reduce the incidence of obesity ${ }^{7}$.

\footnotetext{
${ }^{1}$ Department of Food and Nutrition, Yonsei University, Seoul, 03722, South Korea. ${ }^{2}$ Department of Food Science and Biotechnology, Cha University, Seongnam, Gyeonggi-do, 13488, South Korea. ${ }^{3}$ Department of Oceanography, Pusan National University, Busan, 46241, South Korea. ${ }^{4}$ DOCHO Agricultural Co., Ltd., Shinan, Jeollanam-do, 58851, South Korea. *email: leeseungmin@yonsei.ac.kr; kunypark@cha.ac.kr
} 
Other studies have also reported that SS can help to prevent cancer ${ }^{4-6}$, obesity $^{7}$, diabetes $^{8}$, and hypertension ${ }^{9}$, as compared to purified salt $(\mathrm{NaCl})$. Generally, the minerals (except $\mathrm{NaCl}$ ) in $\mathrm{SS}$ include various cations, such as $\mathrm{Mg}, \mathrm{Ca}, \mathrm{K}$, zinc $(\mathrm{Zn})$, and iron $(\mathrm{Fe})^{3}$. Few studies have reported the relationship between minerals present in the salt composition and obesity. In our previous studies of interaction between SS intake and obesity ${ }^{7,17}$, the Na:K ratio and $\mathrm{Mg}$ content in SS correlate with obesity in mice $^{7}$ and 3T3-L1 adipocytes ${ }^{17}$. These results suggest that the beneficial health effects of SS are due to the presence of various minerals.

$\mathrm{Mg}$ is an essential cation essential for human homeostasis and supporting the physiological functions in the heart, brain, and skeletal muscles. The daily intake of $\mathrm{Mg}$, as suggested by the United States Food and Nutrition Board is $420 \mathrm{mg}$ and $320 \mathrm{mg}$ for men and women, respectively ${ }^{18}$. On the other hand, current reports estimate that only $40 \%$ of Americans consume the required daily amount ${ }^{19}$. Several studies have indicated an association between the body mass index (BMI) and Mg intake status in humans ${ }^{20-23}$, but because these results are controversial ${ }^{24}$, the relationship between obesity and $\mathrm{Mg}$ remains unclear ${ }^{25}$.

Depending on their manufacturing process, salt crystals differ in shape. $\mathrm{NaCl}$ is produced using an ion exchange membrane and subsequently blended to a powder, whereas SS is crystallized by the direct evaporation of sea water, using sunlight and wind. The method of sea water crystallization is an important step ${ }^{26}$. Typically, manufactured SS is a mixture of old- and new seawater during evaporation (generally manufactured sea salt, GS), whereas another process using only new sea water during evaporation produces cube natural sea salt (CNS). This results in differing sizes, shapes, textures, and mineral contents of $\mathrm{Mg}$ and $\mathrm{S}$.

\section{Results}

CNS reduces obesity in azoxymethane/dextran sodium sulfate + high fat diet induced colorectal cancer and obesity on C57BL/6 mice. As presented in Fig. 1A, the dextran sodium sulfate treatment reduces the weight of mice at two and four weeks. At seven weeks, the weight of the mice was observed to be the highest in the high fat diet group $(32.2 \pm 3.7 \mathrm{~g})$, whereas the Normal $(27.1 \pm 1.2 \mathrm{~g}), \mathrm{A} / \mathrm{D}+\mathrm{HFD}$ (azoxymethane (A)/dextran (D) + high fat diet (HFD)) $(26.4 \pm 0.9 \mathrm{~g}), \mathrm{A} / \mathrm{D}+\mathrm{HFD}+\mathrm{GS}(26.3 \pm 1.7 \mathrm{~g})$, and A/D + HFD + FS (FS, filtering sea water after evaporating sea salt $)(26.2 \pm 1.1 \mathrm{~g})$ groups showed similar weights. The A/D $+\mathrm{HFD}+\mathrm{CNS}$ group $(24.3 \pm 1.0 \mathrm{~g})$ showed significantly lower body weight than the A/D + HFD group (Fig. $1 \mathrm{~A})$. At eight weeks (after fasting, except HFD), all mice body weights were similar, except for the HFD group. The normal group had a significantly different average food intake (AFI) compared to the other groups (Supplement Fig. 1A). The $\mathrm{A} / \mathrm{D}+\mathrm{HFD}$-treated groups had a significantly different AFI compared to the HFD group at two and four weeks during the DSS treatment period, whereas at three and five-six weeks, the A/D + HFD groups were similar to the others. The normal group had a significantly increased food conversion ratio (FCR) compared to the HFD group at six and seven weeks (Supplement Fig. 1B). At two and four weeks, the standard deviations of the FCRs of the $\mathrm{A} / \mathrm{D}+\mathrm{HFD}$ as well as A/D + HFD + GS, FS, and CNS groups were large, and the FCR increased because the body weight gain value was negative upon the administration of $\mathrm{D}$. At three and five-seven weeks, however, the group treated with A/D did not show a significant difference overall. The liver, testis, and kidney weights were similar among the groups (data not shown). Therefore, the A/D + HFD + CNS group had the lowest body weight at seven weeks, and $1 \%$ sea salt intake had no effect on AFI or FCR in mice.

The consumption of a HFD is associated with an increased size and number of adipocytes ${ }^{27}$. The epididymal fat size of all mice fed HFD was larger than that of normal mice. The CNS-treated mice showed a significantly reduced fat size and inflammation compared to the A/D + HFD group (Fig. 1B,C) as well as a significantly reduced epididymal fat weight compared the A/D + HFD group $(P<0.05)$ (Fig. 1D). Therefore, the CNS treatment reduced the fat size and weight in the fat and liver tissues as well as the body weight of A/D + HFD-induced mice.

The sterol regulatory element-binding protein 1 (SREBP-1) and fatty acid synthase (FAS) expression levels were elevated in the HFD group and significantly lower in all groups treated with A/D compared to the HFD group (Fig. 2A). On the other hand, in the case of peroxisome proliferator-activated receptor gamma (PPAR $\gamma$ ), the A/D + HFD and A/D + HFD + GS groups were similar to the HFD group, whereas the A/D + HFD + FS and A/D + HFD + CNS groups showed lower PPAR $\gamma$ expression than the HFD group. In particular, the $\mathrm{A} / \mathrm{D}+\mathrm{HFD}+\mathrm{CNS}$ group showed the lowest level of PPAR $\gamma$ mRNA expression, similar to that of the Normal group (Fig. 2A). The A/D-treated groups also showed lower diglyceride acyltransferase 2 (DGAT2) mRNA expression than the HFD group, and the A/D + HFD + CNS group showed the lowest DGAT2 expression $(P<0.05)$ (Fig. 2B). The lipoprotein lipase (LPL) and DGAT2 levels were up-regulated in the HFD group compared to the Normal group (Fig. 2B,C). The A/D + HFD and A/D + HFD + GS groups showed the highest LPL and DGAT2 protein expression levels. On the other hand, the A/D + HFD + CNS group showed significantly lower LPL and DGAT2 levels in the liver and epididymal fat tissues compared to the A/D + HFD and A/D + HFD + GS groups $(P<0.05)$, whereas DGAT2 expression was similar to the Normal group.

Overall, CNS intake reduces obesity compared to other types of sea salt in A/D + HFD induced mice. On the other hand, the A/D + HFD model is a dual disease-induced mouse model. In this model, the mouse body weight loss and reduction of obesity-related gene expression cannot be attributed directly to the sea salt or A/D treatment. Therefore, this study investigated the relationship between sea salt and obesity in 3T3-L1 adipocytes and HFD-induced obese mice.

CNS treatment reduces obesity in 3T3-L1 adipocytes. The survival rate of the $1 \%$ sea salt groups was not reduced significantly (Supplement Fig. 2A). NaCl was not used in the experiment because of the significantly different cytotoxicity between $\mathrm{NaCl}$ and $\mathrm{CNS}$ (Supplement Fig. 2B). In addition, $1 \% \mathrm{CNS}$ reduced the cell viability of differentiated 3T3-L1 adipocytes compared to other salts (Supplement Fig. 2C).

CNS resulted in a significant reduction of Oil red O-stained fat compared to the Control, GS, and FS (Fig. 3A,B). CNS resulted in significantly decreased mRNA expression levels of PPAR $\gamma(0.39 \pm 0.3)$, SREBP-1 
A.

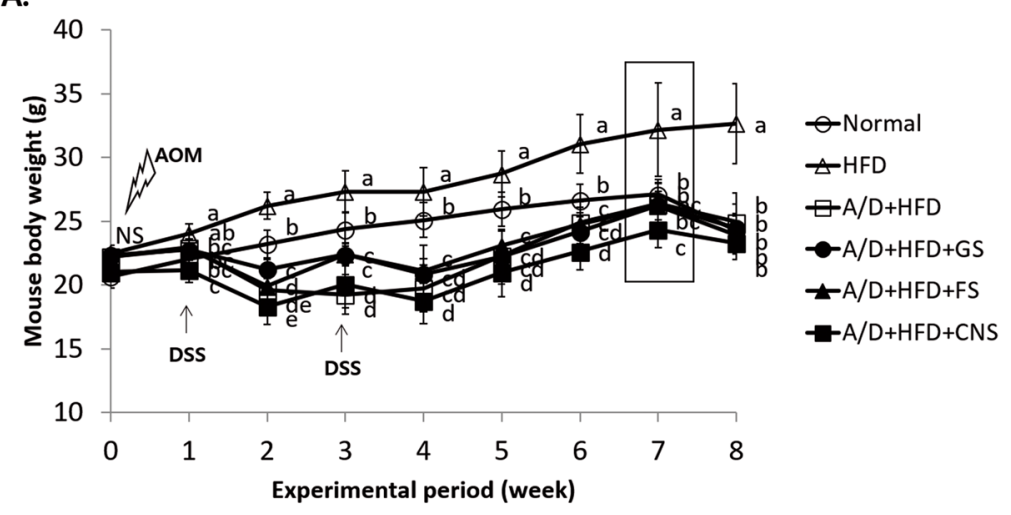

B.

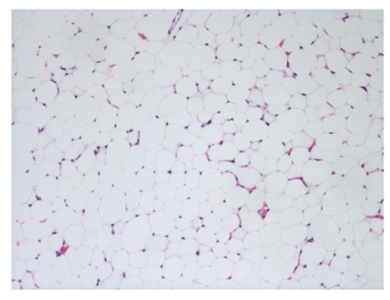

Normal

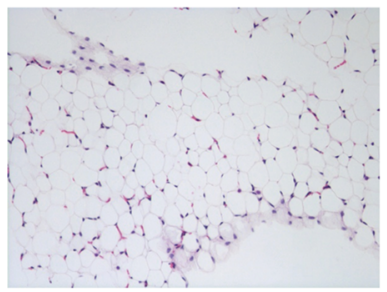

A/D+HFD+GS

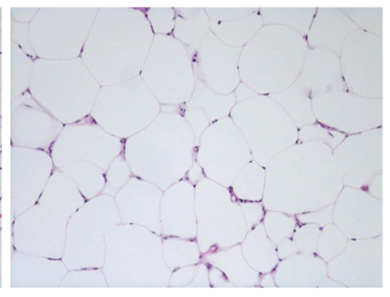

HFD

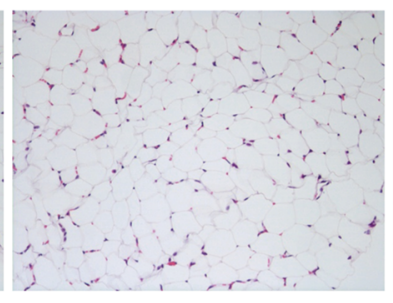

$A / D+H F D+F S$

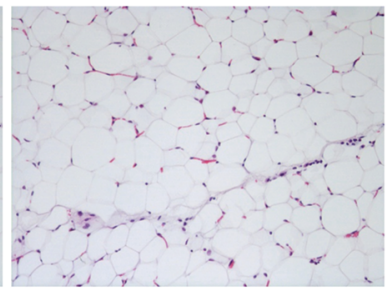

A/D+HFD

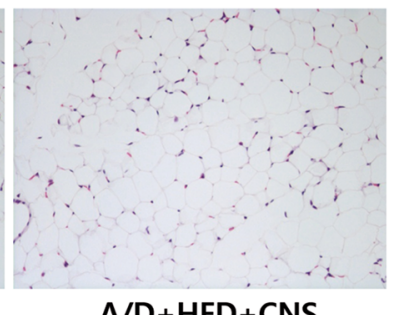

C.
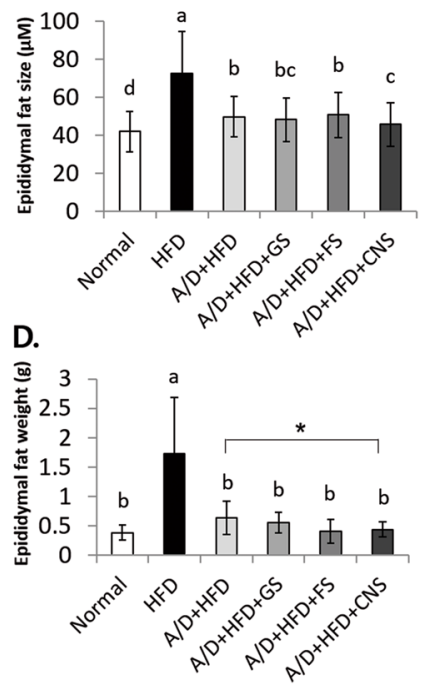

Figure 1. Cube natural sea salt (CNS) intake reduces mouse body weight, as well as number of lipid droplets and weight of epididymal adipose tissue. (A) Mouse body weight and histological analysis of epididymal adipose tissue and fat size, and body weight of C57BL/6 mice treated with A/D, HFD, and A/D + HFD.

(B) Epididymal adipose tissue was observed using a light microscope following H\&E staining (C) Epididymal adipose tissue size and (D) weight are shown. ${ }^{\mathrm{a}-\mathrm{d}}$ Means with different letters on the bars are significantly different $(P<0.05)$ by Duncan's multiple range test. Magnification $\times 100$.

$(0.42 \pm 0.21)$, CCAAT-enhancer-binding proteins alpha $(\mathrm{C} / \mathrm{EBP} \alpha)(0.14 \pm 0.04)$, liver X receptor alpha $(\mathrm{LXR} \alpha)$ $(0.22 \pm 0.17)$, FAS $(0.44 \pm 0.15)$, DGAT2 $(0.53 \pm 0.21)$, and LPL $(0.42 \pm 0.32)$ in differentiated 3T3-L1 adipocytes compared to the Control $(P<0.05)$ (Fig. 3C). In addition, CNS resulted in significantly reduced levels of SREBP-1 protein expression $(0.42 \pm 0.02)$ compared to the Control (fold ratio: 1$)(P<0.05)$ (Fig. 3D). Therefore, CNS inhibits adipo/lipogenesis via the regulation of related gene expression.

CNS intake reduces the basic parameters of obesity compared to $\mathrm{NaCl}$ and GS intake in high fat diet induced obese mice. A high fat diet (HFD) group of animals gains more weight than those fed a normal diet. Because this study focused on the interaction between HFD and salt samples, only the HFD and HFD + sample treated groups were compared; a normal diet group was not included. As shown in Fig. 4A, a significant decrease in body weight was observed in the CNS treatment group as compared to the $\mathrm{NaCl}$ (Reagent, Sigma-Aldrich Co., St. Louis, MO, USA) group at $12-16$ weeks $(P<0.05)$. At 17 weeks, the reduction in body weight was significantly different in the CNS group $(36.2 \pm 4.9 \mathrm{~g})$ than both the $\mathrm{NaCl}$ group $(42.5 \pm 3.5 \mathrm{~g})$ and GS group $(41.5 \pm 5.0 \mathrm{~g})(P<0.05)$ (Fig. 4B). No significant difference in the AFI was observed between the groups (Supplement Fig. 3A). On the other hand, the CNS group had a significantly higher FCR than the HFD group at 16 and 17 weeks (Supplement Fig. 3B). At nine weeks, all mice inadvertently showed a decrease in body weight with a reduced AFI and enhanced FCR. After nine weeks, however, the body weight, AFI, and FCR of all the mice returned to normal conditions.

The measured serum lipids profiles revealed a significant reduction of triglyceride (TG), total cholesterol (TC), and low density lipoprotein (LDL) in the CNS group as compared to the $\mathrm{NaCl}$ group $(P<0.05)$ (Fig. 4C). In addition, the CNS group showed significantly reduced leptin levels (a serum obesity related hormone) as compared to $\mathrm{HFD}, \mathrm{NaCl}$, and GS groups $(P<0.05)$ (Fig. 4D). The liver enzyme concentrations showed significant reduction of aspartate transaminase (AST) and alanine transaminase (ALT) in the CNS group as compared to the $\mathrm{NaCl}$ group 


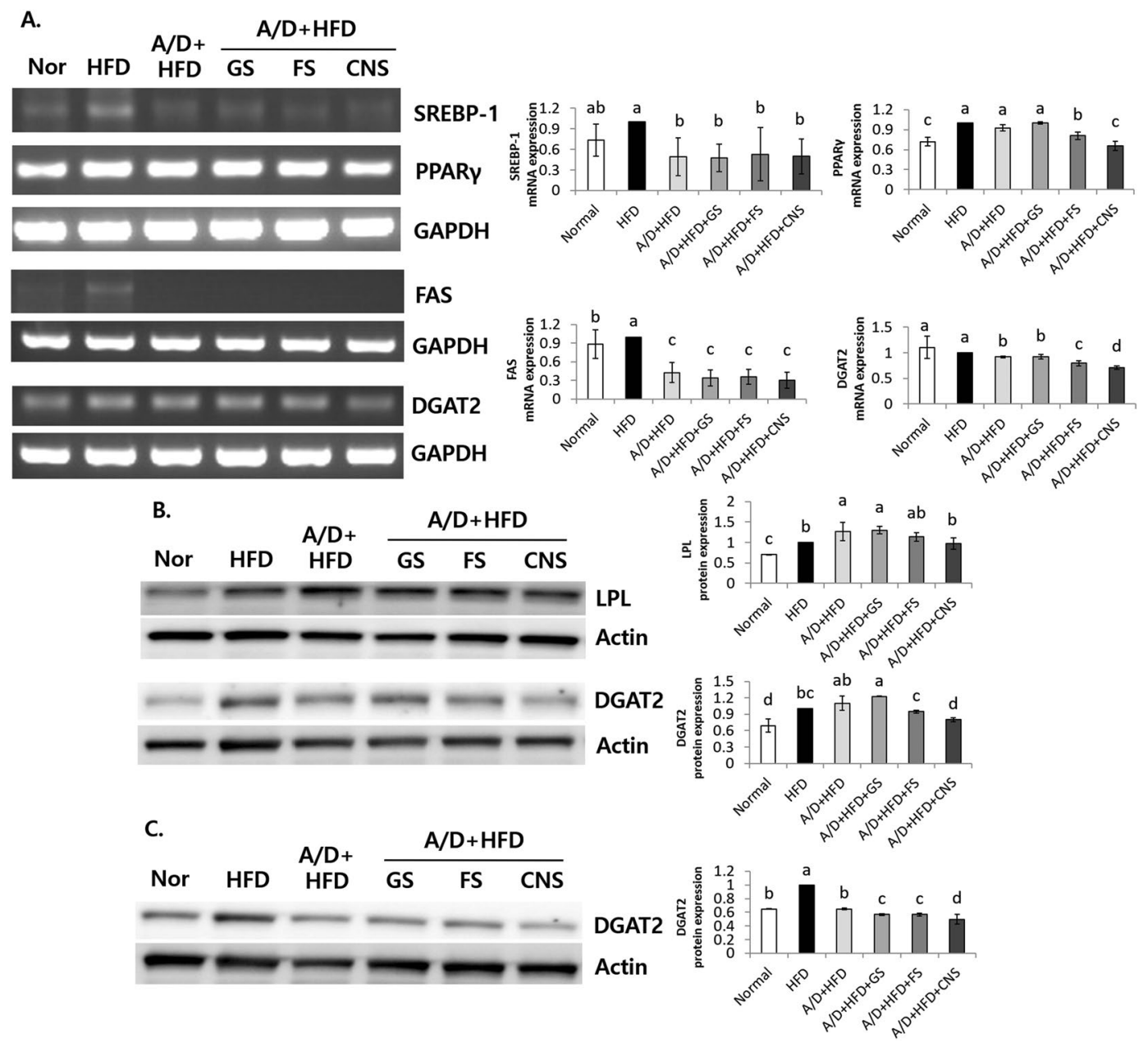

Figure 2. CNS regulates obesity related genes in A/D + HFD induced mice. (A) Adipo/lipogenesis related genes of mRNA expression levels of SREBP-1, PPAR $\gamma$, FAS, and DGAT2 in liver tissue. (B) protein expression levels of the lipogenesis genes LPL and DGAT2 in the liver and (C) epididymal fat. Fold ratio: Gene expression/ $($ GAPDH or Actin $) \times$ HFD numerical value $($ HFD fold ratio $=1)$. ${ }^{\text {a-d }}$ Means with different letters are significantly different $(P<0.05)$ by Duncan's multiple range test. The grouping of gels/blots cropped from different gels/blots.

$(P<0.05)$ (Fig. 4E). On the other hand, the Na concentrations and glucose level in the serum remained unaffected with all salt treatments (Supplement Fig. 4A,B), indicating that the type of salt has no effect on the glucose metabolism, and $1 \%$ salt intake does not influence blood homeostasis in mice.

These observations showed that the CNS group had the lowest body weight at 17 weeks. Although the AFI or FCR were unaffected by $1 \% \mathrm{NaCl}$ and the sea salt intake, the CNS group showed enhanced FCR at 16 and 17 weeks. In addition, the serum examination revealed reduced lipid accumulation, leptin and liver enzymes in the CNS group. Overall, $\mathrm{NaCl}$ intake increases obesity, but the CNS intake results in decreased obesity compared to $\mathrm{NaCl}$ intake in HFD-induced obese mice.

CNS intake regulates fatty liver, fat size, and expression of genes related to adipo/lipogenesis, $\beta$-oxidation, and lipolysis in liver and epididymal white adipose tissue in high fat diet induced obese mice. As shown in Fig. 5A, HFD induces the accumulation of lipid droplets and weight growth in liver tissue. The $\mathrm{NaCl}$ group had highly accumulated lipid droplets and increased number of inflammatory cells, loss of nuclei, and severe swelling of hepatocytes as compared to the other groups. The CNS group showed significantly reduced lipid droplets and number of inflammatory cells compared to the HFD, $\mathrm{NaCl}$, and GS groups. The liver weight was significantly decreased in the CNS group $(1.08 \pm 0.47 \mathrm{~g})$ as compared to the $\mathrm{NaCl}$ group $(1.74 \pm$ $0.48 \mathrm{~g})$.

Considering the adipo/lipogenesis related transcription factors, namely, SREBP-1, C/EBP $\alpha$, and LXR $\alpha$, the CNS group showed significantly lower mRNA expression than the HFD and $\mathrm{NaCl}$ groups $(P<0.05)$ (Fig. 5B). In addition, the expression levels of the lipogenesis-related genes of FAS, glycerol-3-phosphate acyltransferase 2 (GPAT2), DGAT1, and LPL were also significantly reduced in the CNS group when compared to HFD and $\mathrm{NaCl}$ groups $(P<0.05)$ (Fig. 5 C,D). In particular, the CNS group $(1.44 \pm 0.28)$ showed higher levels of mRNA expression of a $\beta$-oxidation related gene, carnitine palmitoyltransferase 1 (CPT-1), than the $\mathrm{NaCl}$ group $(0.57 \pm 0.07)$ 
A.

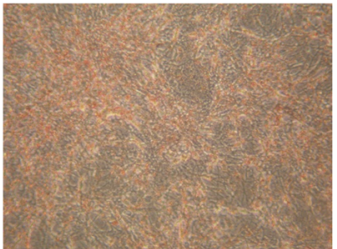

Control

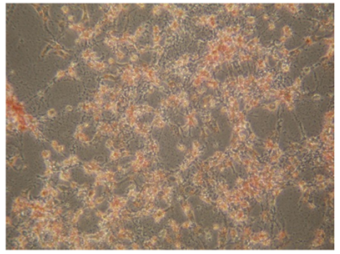

FS

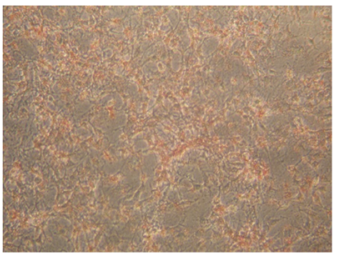

GS

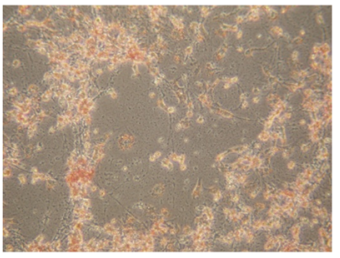

CNS
B.

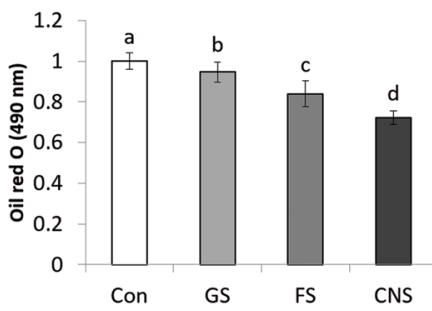

C.

Con GS FS CNS

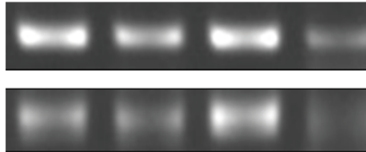

PPARY
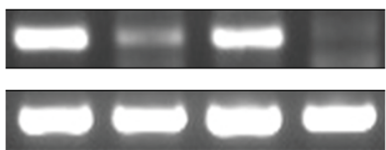

$\mathrm{C} / \mathrm{EBP} \alpha$

GAPDH
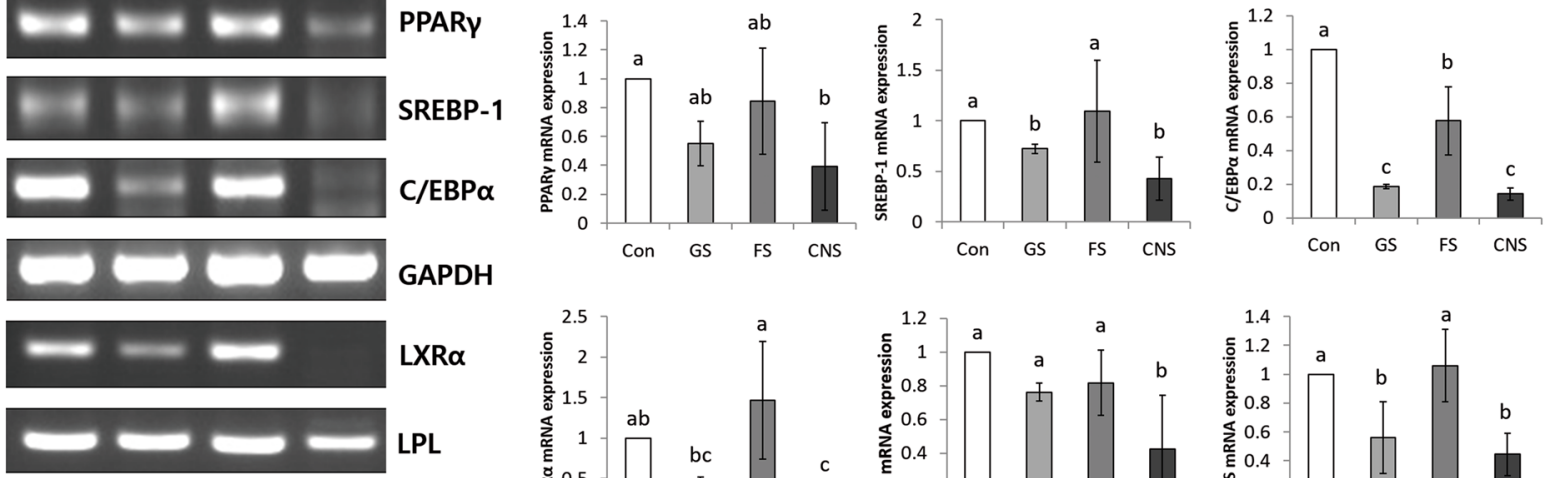

LXR $\alpha$

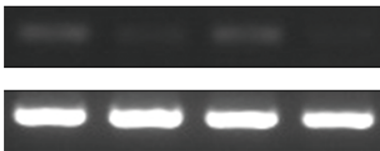

LPL

FAS
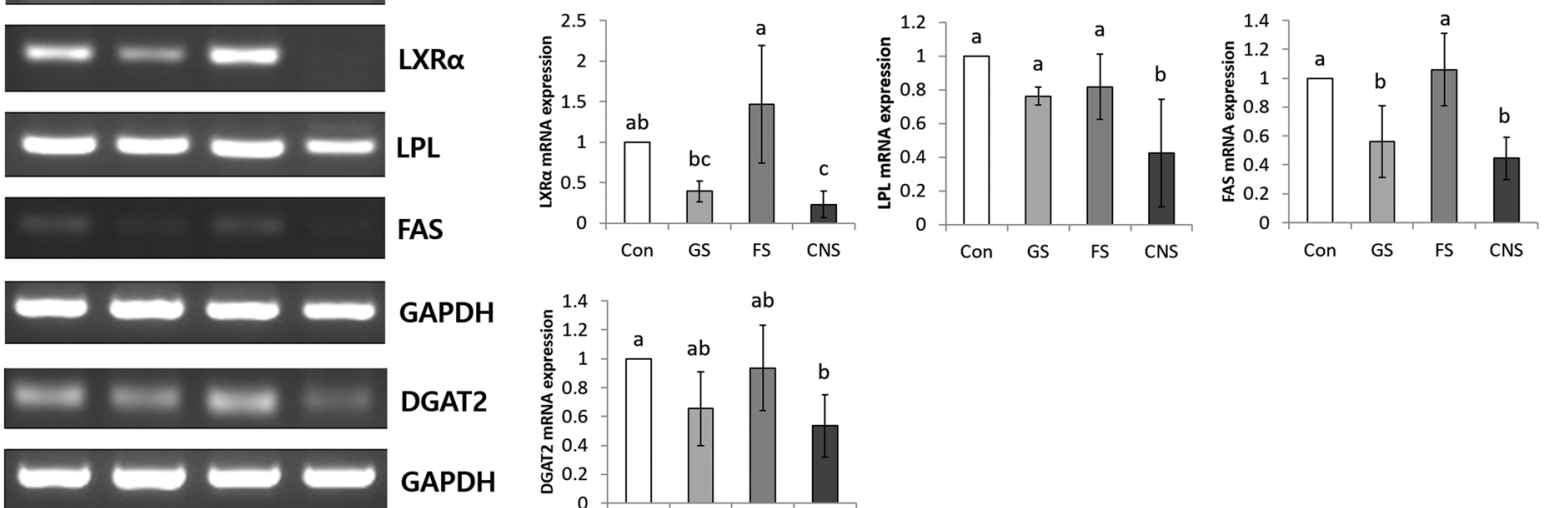

GAPDH

DGAT2

GAPDH

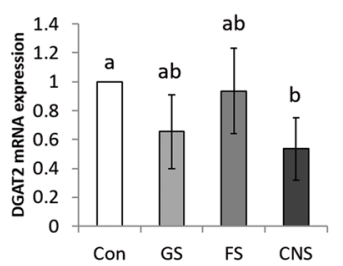

D.

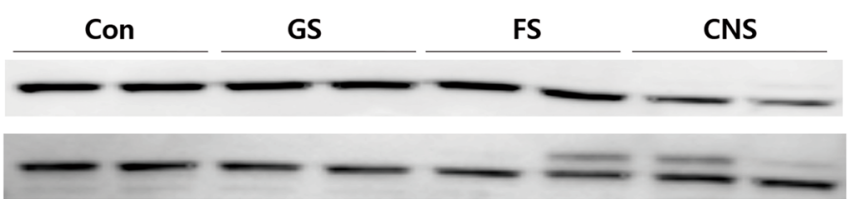

SREBP-1

Actin

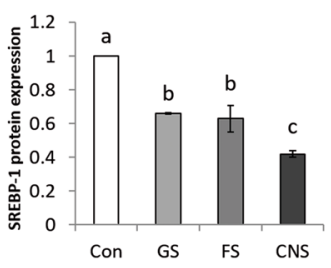

Figure 3. CNS treatment reduces lipid droplet and obesity related genes in differentiated 3T3-L1 adipocytes. (A) Oil red O staining, (B) $490 \mathrm{~nm}$ absorbance value, (C) mRNA expression levels of the adipo/lipogenesisrelated genes PPAR $\gamma, \mathrm{SREBP}-1, \mathrm{C} / \mathrm{EBP} \alpha, \mathrm{LXR} \alpha, \mathrm{LPL}, \mathrm{FAS}$, and DGAT2, and (D) protein expression levels of SREBP-1 in differentiated 3T3-L1 adipocytes. GS: Generally manufactured sea salt (mixture of concentrated old and new seawater) (1\%), FS: Filtering processed sea salt (mixture of concentrated old and new seawater filtered through a charcoal and magnetic filter) (1\%), CNS: Cube natural sea salt (sea salt made from only concentrated new seawater) $(1 \%)$. Fold ratio: Gene expression/(GAPDH or Actin) $\times$ Control numerical value (Control fold ratio $=1)$. The grouping of gels/blots cropped from different gels/blots.

(Fig. 5E). Furthermore, the CNS group $(1.42 \pm 0.21)$ also showed enhanced levels of the lipolysis-related gene of hormone sensitive lipase (HSL) compared to the $\mathrm{NaCl}$ group $(0.57 \pm 0.09)(P<0.05)($ Fig. $5 \mathrm{~F})$. The protein levels of DGAT1 and 2, were lower, whereas the CPT-1 levels were higher in the CNS group (1.01 \pm 0.01$)$ than the $\mathrm{NaCl}$ group $(0.61 \pm 0.13)(P<0.05)$ (Fig. $5 \mathrm{G})$. Considering adipo/lipogenesis, the $\mathrm{NaCl}$ group showed significantly increased FAS compared to the HFD group, but in $\beta$-oxidation and lipolysis, the $\mathrm{NaCl}$ group markedly showed decreased CPT-1 and HSL compared to the HFD group. These results indicate that consumption of $\mathrm{NaCl}$ may 
A.

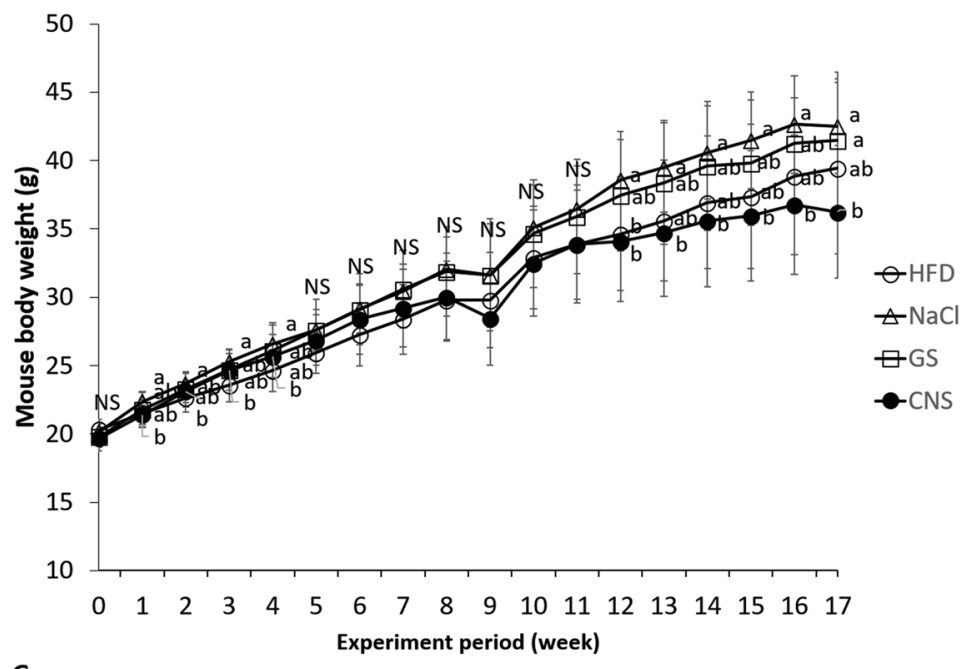

B.

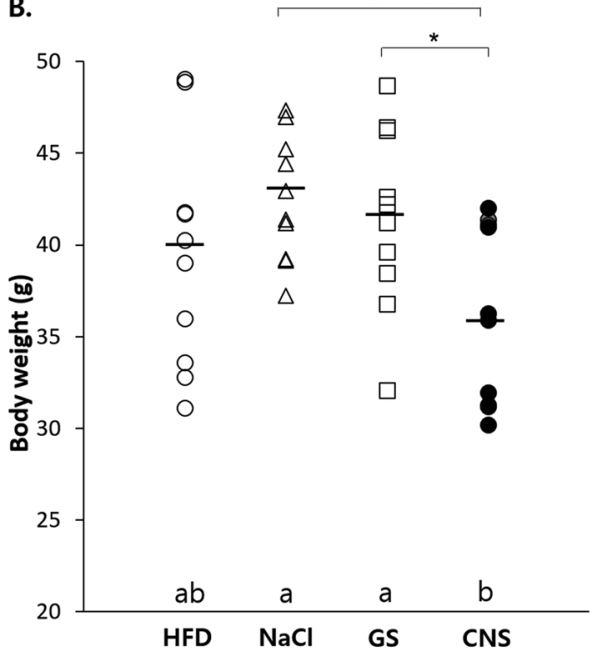

C.
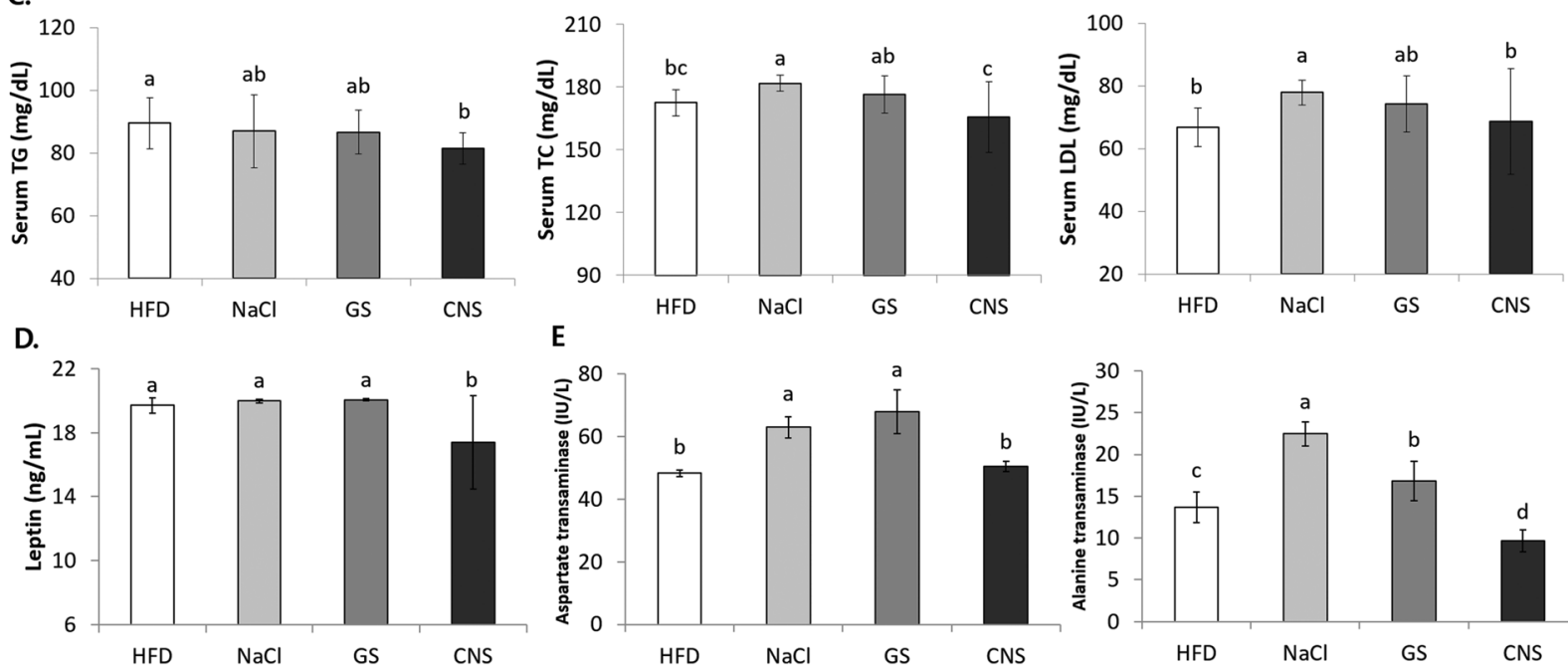

$$
\text { E }
$$
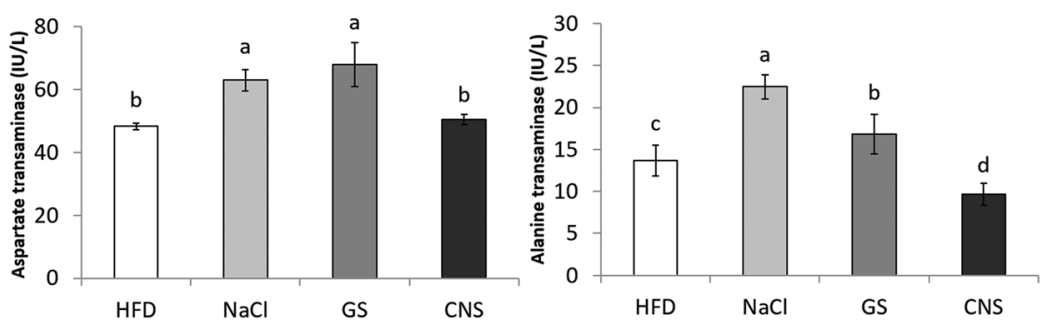

Figure 4. CNS intake reduces basic parameters of obesity in high fat diet induced obese mice. (A) Mouse body weight calculated at 0-17 weeks. (B) Mouse body weight at 17 weeks, expressed individually. (C) Lipid profiles of TG, TC, and LDL level in mice serum. (D) Levels of leptin, an obesity related hormone, in mice serum. (E) Liver enzyme activity of AST and ALT in mice serum. HFD: $45 \%$ high fat diet, $\mathrm{NaCl}: 45 \%$ high fat diet $+\mathrm{NaCl}$ (reagent) (1\%), GS: 45\% high fat diet + generally manufactured sea salt (mixture of concentrated old and new seawater) (1\%), CNS: $45 \%$ high fat diet + Cube natural sea salt (sea salt made from only concentrated new seawater) $(1 \%) .{ }^{\mathrm{a}-\mathrm{c}}$ Means with different letters are significantly different $(P<0.05)$ by Duncan's multiple range test.

suppress the expression of $\beta$-oxidation and lipolysis in the liver tissue, thereby enhancing obesity by improving the levels of lipid accumulation and body weight gain. On the other hand, CNS intake inhibited adipo/lipogenesis and promoted $\beta$-oxidation and lipolysis via the regulation of related gene expression compared to the HFD and $\mathrm{NaCl}$ groups, and showed better suppression of obesity.

As shown in Fig. 6A, HFD induced an increase in the amounts of fat in the epididymal white adipose tissue of mice. The HFD and $\mathrm{NaCl}$ groups showed a significantly increased fat size, number of inflammatory cells, loss of nuclei, and crown-like structures compared to the other groups. The CNS group $(1.75 \pm 0.57 \mathrm{~g})$ had significantly lower epididymal white adipose tissue weight as compared to the $\mathrm{NaCl}$ group $(2.32 \pm 0.64 \mathrm{~g})$. Moreover, the CNS group $(79.0 \pm 20.9 \mu \mathrm{m})$ also showed significantly reduced epididymal white adipocyte size as compared to the $\mathrm{NaCl}(96.8 \pm 27.1 \mu \mathrm{m})$ and $\mathrm{HFD}(100.7 \pm 22.2 \mu \mathrm{m})$ groups.

In the CNS group significantly decreased mRNA expression levels of the adipo/lipogenesis related transcription factors, $\mathrm{LXR} \alpha$ and $\mathrm{C} / \mathrm{EBP} \alpha$, were observed compared to the $\mathrm{NaCl}$ group $(P<0.05)$ (Fig. 6B). Furthermore, the lipogenesis related genes of FAS also showed significantly reduced mRNA expression in the CNS group as compared to $\mathrm{NaCl}$ group $(P<0.05)$ (Fig. $6 \mathrm{C}$ ). The $\mathrm{CNS}$ group promoted the mRNA expression of the $\beta$-oxidation related gene, CPT-1 $(13.23 \pm 4.40)$, compared to the $\mathrm{NaCl}$ group $(4.35 \pm 1.09)(P=0.072)$ (Fig. $6 \mathrm{D})$. Regarding the protein levels, the CNS group showed significantly decreased protein levels of C/EBP $\alpha$ and FAS when compared to the $\mathrm{NaCl}$ group (Fig. 7E). In addition, the $\mathrm{NaCl}$ group revealed significantly increased mRNA expression 
A.
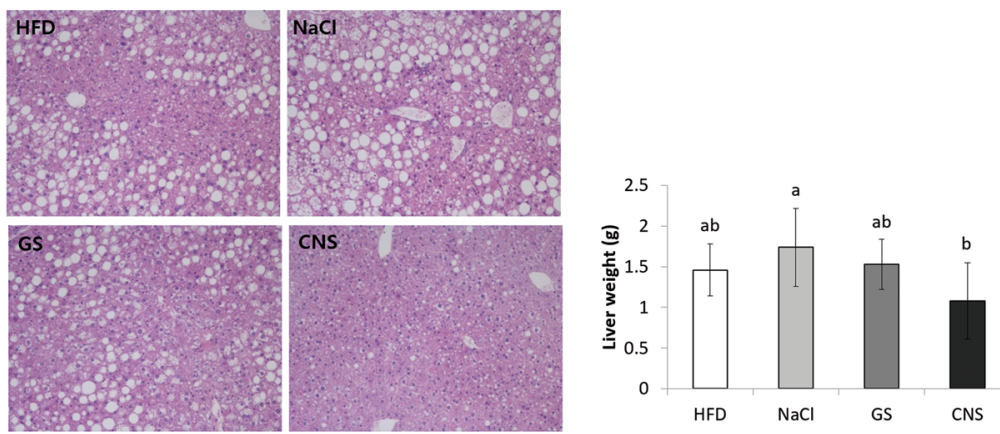

B.
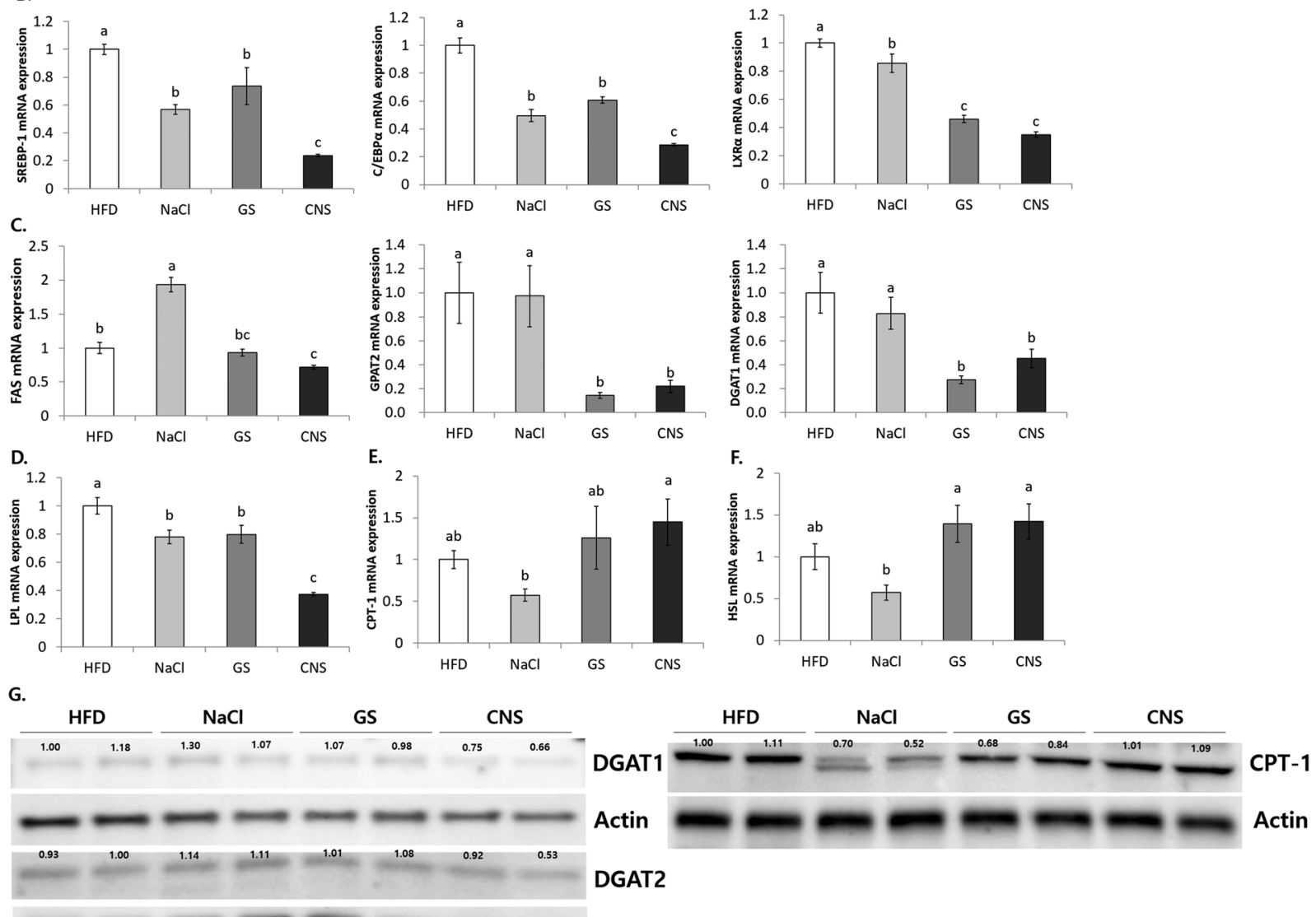

Actin

Figure 5. CNS intake reduces lipid droplet and regulates obesity related gene expression in liver tissue. (A) Histological observation of hematoxylin and eosin (H\&E) stained liver tissue, and corresponding liver tissue weight. (B-F) mRNA expressions of: (B) adipo/lipogenesis related transcription factor genes, (C) triglyceride storage (lipogenesis) related genes, (D) gene related to regulation of triglyceride and cholesterol storage or release by chylomicron, (E) $\beta$-oxidation related gene, and (F) lipolysis related gene. (G) Protein expressions of lipogenesis and $\beta$-oxidation related genes. ${ }^{\mathrm{a}-\mathrm{c}}$ Means with different letters are significantly different $(P<0.05)$ by Duncan's multiple range test. Gene expression/Actin $\times$ HFD numerical value (HFD fold ratio $=1)$ used ImageJ program. The grouping of blots cropped from different blots.

of $\mathrm{LXR} \alpha, \mathrm{C} / \mathrm{EBP} \alpha$, and FAS, but decreased protein levels of $\mathrm{C} / \mathrm{EBP} \alpha$ and FAS as compared to the HFD group. As indicated previously, $\mathrm{NaCl}$ decreases the mRNA expression of transcription factors of adipo/lipogenesis related genes in the liver (Fig. 5B). In particular, the feces lipid levels remained unaffected by all salt treatments (Supplement Fig. 5). Therefore, $\mathrm{NaCl}$ intake has a strong influence on $\beta$-oxidation and lipolysis, as against adipo/ lipogenesis in the mouse liver. The reduced fat oxidation and lipolysis due to $\mathrm{NaCl}$ intake may therefore be associated with the accumulation of excess fat. However, sea salt (GS and CNS) intake inhibits adipo/lipogenesis and promotes $\beta$-oxidation in epididymal white adipose tissue when compared to $\mathrm{NaCl}$, and especially, $\mathrm{CNS}$ intake was seen to be more efficacious than GS. 
A.
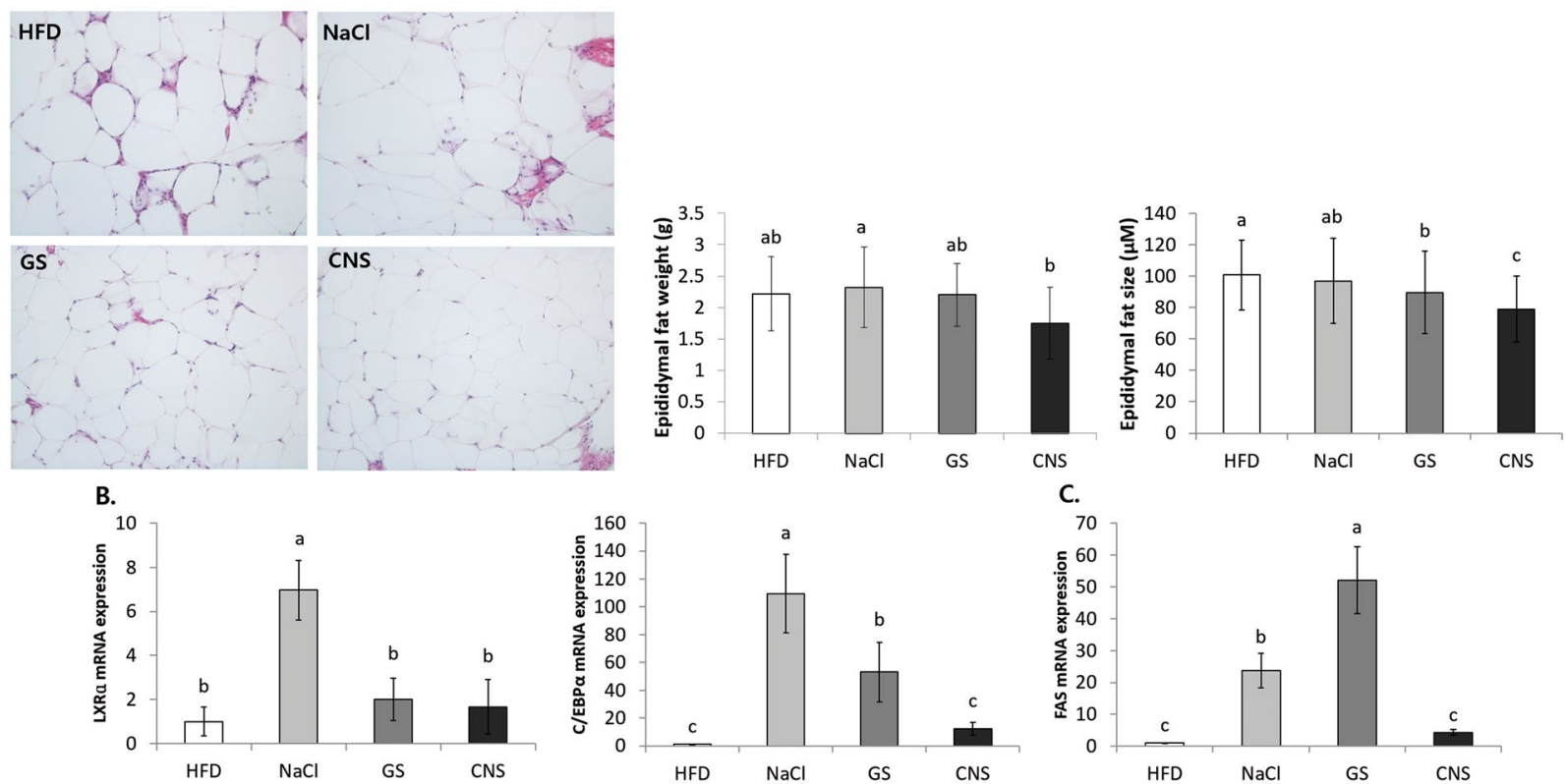

C.
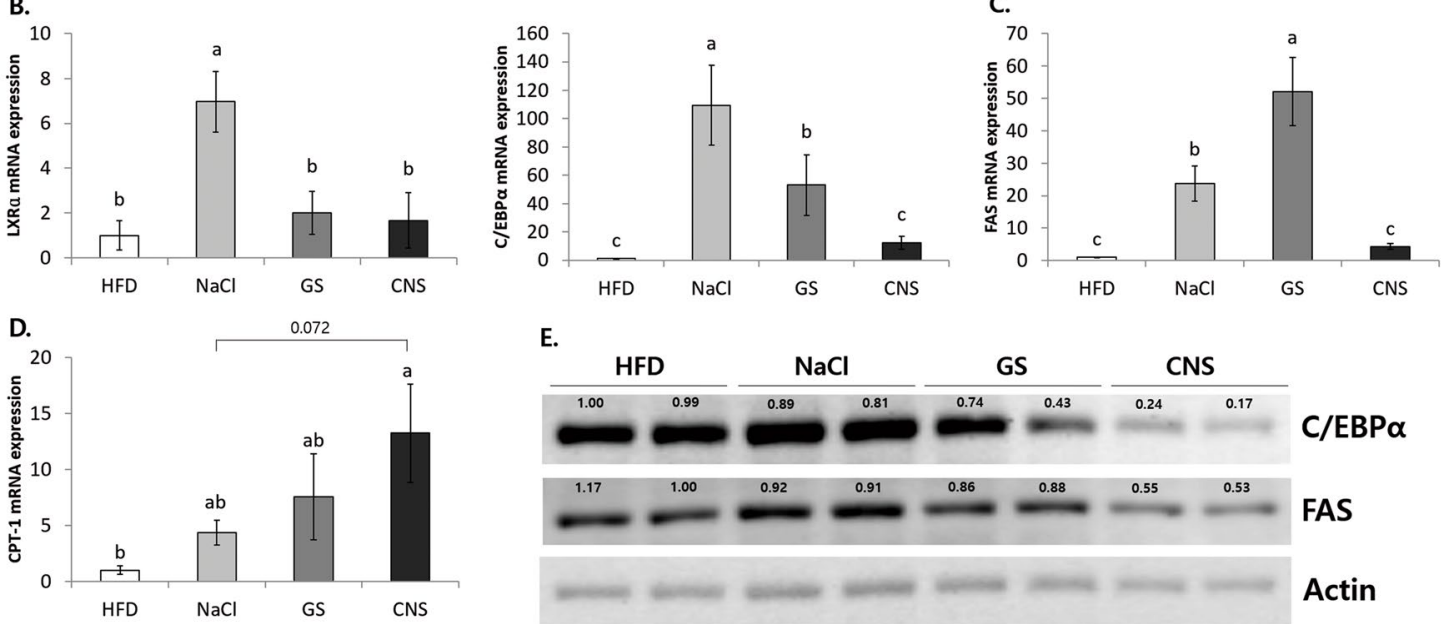

E.

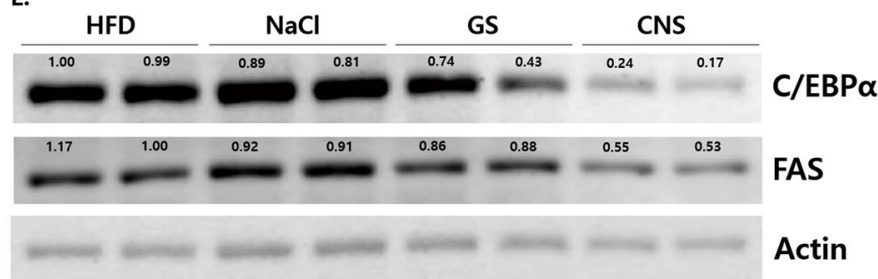

Figure 6. CNS intake decreases fat size and weight, and regulates obesity related gene expression in epididymal white adipose tissue. (A) Histological observation of epididymal fat tissue using hematoxylin and eosin (H\&E) staining, and corresponding weight and size of fat tissue. (B-D) mRNA expressions of (B) adipo/lipogenesis related transcription factor genes, $(\mathbf{C})$ triglyceride storage (lipogenesis) related genes, and (D) $\beta$-oxidation related gene. (E) Protein expressions of adipo/lipogenesis related genes. ${ }^{\mathrm{a}-\mathrm{c}}$ Means with different letters are significantly different $(P<0.05)$ by Duncan's multiple range test. Gene expression/Actin $\times$ HFD numerical value $($ HFD fold ratio $=1)$ used Image program. The grouping of blots cropped from different blots.

Manufacturing process of salts affects the cation, anion, assemblage, and morphology. The chemical composition of dissolved sea salt samples (GS and CNS) revealed different elemental concentrations of cations when compared to the $\mathrm{NaCl}$ (Table 1). High concentrations of $\mathrm{Mg}$ and $\mathrm{S}$ with low concentrations of Fe were present in the sea salt samples as compared to the $\mathrm{NaCl}$ of control sample. Both $\mathrm{Cu}$ and $\mathrm{P}$ were absent. Different concentrations of cations were present in the two types of sea salt (GS and CNS). GS contained more Mg, $\mathrm{Ca}, \mathrm{S}, \mathrm{Zn}$, and $\mathrm{Fe}(5.3,1.6,9.4,1.1$, and 3.6 times, respectively) as compared to $\mathrm{CNS}$, whereas $\mathrm{Na}$ and $\mathrm{K}$ contents were lacking (less than $0.77 \%$ and $0.87 \%$, respectively).

The appearance of salts varies according to their processing. In this study, the three types of salts had different appearances. In particular, the shape of CNS was cubic, which is produced naturally (Fig. 7A).

The analysis results of all three samples showed that the $\mathrm{Cl}^{-}$content was higher than $\mathrm{SO}_{4}{ }^{2-}$. $\mathrm{GS}$ had lower $\mathrm{Cl}^{-}$ than CNS (4214 ppm and $5579 \mathrm{ppm}$, respectively), whereas $\mathrm{SO}_{4}{ }^{2-}$ content was higher (1136 ppm and $430 \mathrm{ppm}$, respectively) (Fig. 7B).

The X-ray diffractometer (XRD) analysis profiles were recorded using the $\mathrm{Cu}$-K X-ray source $(\lambda=1.5406 \AA)$. Profiles were recorded while rotating the randomly oriented samples, enabling us to check the rotation angle during diffraction. Signals were interpreted into diffraction peaks in the XRD profiles ${ }^{28}$. XRD analyses of salts $(\mathrm{NaCl}$, GS, and CNS) were performed for the different manufacturing procedures (Fig. 7C). NaCl of the control sample was examined to confirm the purity of $\mathrm{NaCl}$ and $\mathrm{KCl}$. The heterogeneous suite of minerals identified by XRD in GS includes $\mathrm{ZnSO}_{4}, \mathrm{~K}_{2} \mathrm{SO}_{4}, \mathrm{Na}_{2} \mathrm{SO}_{4}, \mathrm{MgSO}_{4}$, and $\mathrm{NaCl}$. The minerals identified in CNS include $\mathrm{NaCl}, \mathrm{K}_{2} \mathrm{SO}_{4}$, and $\mathrm{MgSO}_{4}$, with $\mathrm{NaCl}$ peaks appearing more prominently as compared to GS. The discernible sulfate mineral $\mathrm{XRD}$ reflections were not observed due to the lack of sulfate, as confirmed by inductively coupled plasma-optical emission spectrometry (ICP-OES) (Table 1).

Scanning electron microscopy (SEM) of the SS samples from GS, CNS, and control showed that the $\mathrm{NaCl}$ mineral typically appeared as aggregates of well-developed euhedral cubic structures (Fig. 7D), clusters of randomly distributed square columnar structure with varied sizes $(\sim 10 \mu \mathrm{m})$ which are confirmed as $\mathrm{MgSO}_{4}$ of sulfate minerals and $\mathrm{NaCl}$ (GS, Fig. 7E), and relatively bigger size crystals of $\mathrm{NaCl}(\sim 25 \mu \mathrm{m})$ that appear to be underdeveloped and were identified to be devoid of the prominent shape of sulfate minerals (CNS, Fig. 7F). 
A.

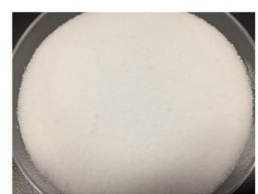

$\mathrm{NaCl}$

B.
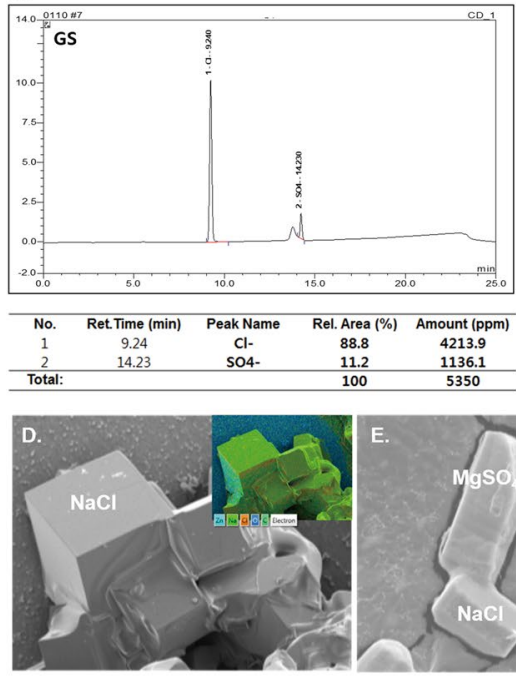

$\sqrt{100 \mu \mathrm{m}}$

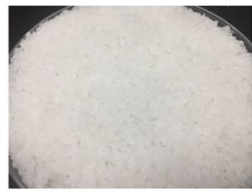

GS

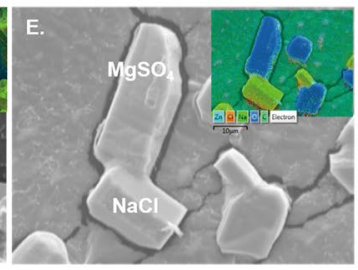

$\longdiv { 1 0 \mu \mathrm { m } }$

CNS
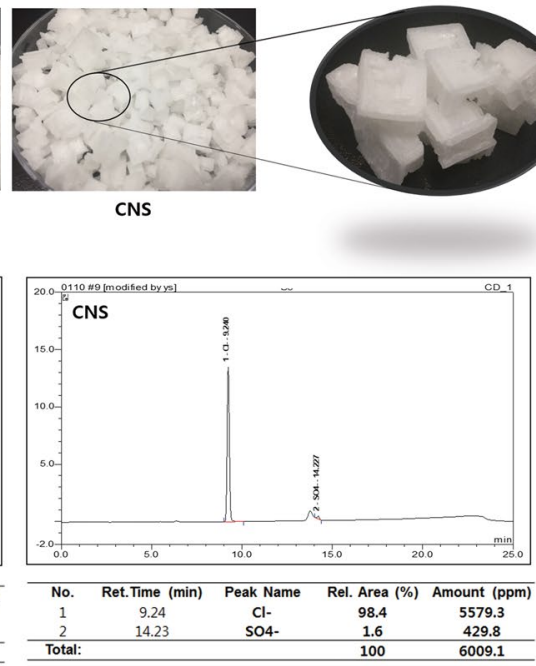

429.8

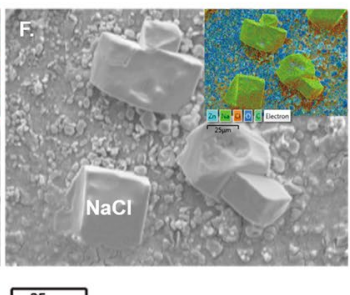

$\longdiv { 2 5 \mu m }$ c.

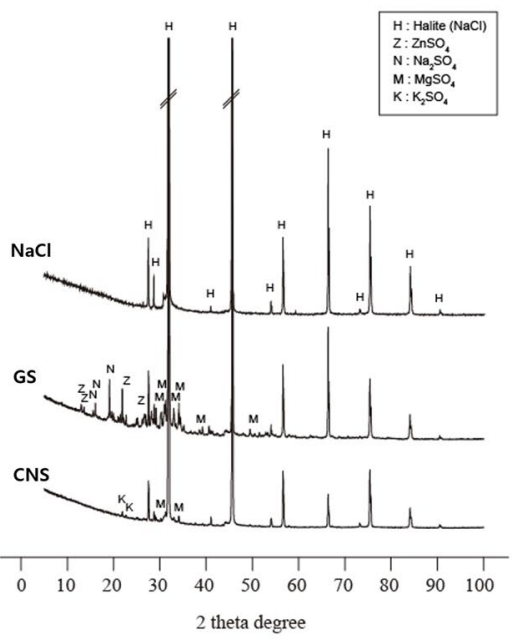

Figure 7. Different manufactured salts have different anion concentration, mineral assemblage, and morphology. (A) Appearance of differently manufactured salts. (B) Anion concentration of three types of solar salts (NaCl, GS, and CNS) by using ion chromatograph (IC) analytical instrument. Anions of two elements $(\mathrm{Cl}$ and $\mathrm{SO}_{4}$ ) were measured (units: ppm). (C) X-ray diffractogram (XRD) profiles for air dried solar salts ( $\mathrm{NaCl}$, $\mathrm{GS}$, and $\mathrm{CNS})$ displaying composition of halite $(\mathrm{NaCl})$, and sulfate mineralized salts of zinc sulfate $(\mathrm{Z})$, sodium sulfate $(\mathrm{N})$, magnesium sulfate $(\mathrm{M})$, and potassium sulfate $(\mathrm{K})$. All three samples show prominent halite $(\mathrm{NaCl})$ peak $\left(31.82^{\circ}, 3.11 \AA\right.$ and $\left.45.541^{\circ}, 1.99 \AA\right)$. (D-F) SEM micrograph of mineralized solar salt structures and inset images of EDS elemental distribution maps. (D) Aggregates of high crystalline of cubic structure of halite $(\mathrm{NaCl})$ in control. (E) Randomly distributed elongated shaped poorly crystalline halite and $\mathrm{MgSO}_{4} \sim 10 \mu \mathrm{m}$ in length in GS. (F) Underdeveloped cubic structure of halite $\sim 25 \mu \mathrm{m}$ with sulfate minerals of few nanometer size in CNS.

\begin{tabular}{|l|l|l|l|}
\hline & NaCl & GS & CNS \\
\hline $\mathrm{Na}(\mathrm{g} / \mathrm{kg})$ & $332.86 \pm 3.51^{\mathrm{a}}$ & $225.56 \pm 5.66^{\mathrm{c}}$ & $294.57 \pm 3.28^{\mathrm{b}}$ \\
\hline $\mathrm{Mg}(\mathrm{g} / \mathrm{kg})$ & Not detected & $41.83 \pm 0.20^{*}$ & $7.96 \pm 0.10$ \\
\hline $\mathrm{K}(\mathrm{g} / \mathrm{kg})$ & $5.59 \pm 0.18^{\mathrm{c}}$ & $8.39 \pm 0.02^{\mathrm{b}}$ & $9.63 \pm 0.24^{\mathrm{a}}$ \\
\hline $\mathrm{Ca}(\mathrm{g} / \mathrm{kg})$ & Not detected & $1.42 \pm 0.02^{*}$ & $0.91 \pm 0.00$ \\
\hline $\mathrm{S}(\mathrm{g} / \mathrm{kg})$ & Not detected & $10.21 \pm 0.16^{*}$ & $5.00 \pm 0.03$ \\
\hline $\mathrm{Zn}(\mathrm{mg} / \mathrm{kg})$ & $0.34 \pm 0.02^{\mathrm{NS}}$ & $0.32 \pm 0.03$ & $0.30 \pm 0.02$ \\
\hline $\mathrm{Fe}(\mathrm{mg} / \mathrm{kg})$ & Not detected & $1.10 \pm 0.06^{*}$ & $0.30 \pm 0.03$ \\
\hline $\mathrm{Cu}(\mathrm{mg} / \mathrm{kg})$ & Not detected & \\
\hline
\end{tabular}

Table 1. Elemental concentration of three types of solar salt samples ( $\mathrm{NaCl}, \mathrm{GS}$, and $\mathrm{CNS}$ ) evaluated by the ICP-OES analytical instrument. Nine cations of elements ( $\mathrm{Na}, \mathrm{Mg}, \mathrm{K}, \mathrm{Ca}, \mathrm{S}, \mathrm{Zn}, \mathrm{Fe}, \mathrm{CU}$, and P) were measured (units: ppm). ${ }^{a-c}$ Means with different letters are significantly different $(P<0.05)$ by Duncan's multiple range test. $*<0.05$ student t-test (between GS and CNS).

An appropriate concentration of $\mathrm{MgCl}_{2}$ is required to regulate obesity. Seawater contains numerous ionized minerals. Because sea salt is produced by the evaporation of seawater, the difference in crystallinity of the constituent minerals varies significantly, depending on the environment in which the minerals are precipitated, including the presence of impurities and the time for recrystallization ${ }^{29}$. We previously demonstrated the presence of $\mathrm{NaCl}, \mathrm{KCl}, \mathrm{ZnSO}_{4}, \mathrm{~K}_{2} \mathrm{SO}_{4}, \mathrm{Na}_{2} \mathrm{SO}_{4}$, and $\mathrm{MgSO}_{4}$ in $\mathrm{NaCl}$ (reagent), GS, and CNS (Fig. 7). However, during consumption, most minerals in salt are dissolved with water and are ionized (Supplement Fig. 6) to release $\mathrm{Na}^{+}, \mathrm{K}^{+}, \mathrm{Ca}^{2+}, \mathrm{Mg}^{2+}, \mathrm{Cl}^{-}$, and $\mathrm{SO}_{4}{ }^{2-30}$, which in turn influence the body. Evaluation of the mineral ions revealed 


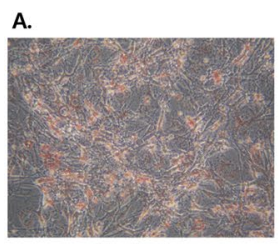

Control

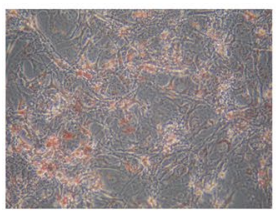

$0.99 \mathrm{mM}$

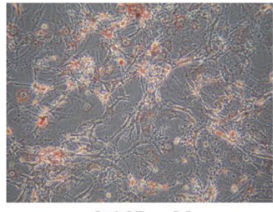

$0.165 \mathrm{mM}$

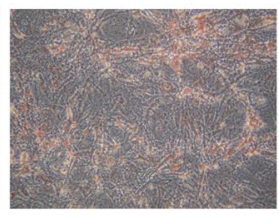

$1.65 \mathrm{mM}$

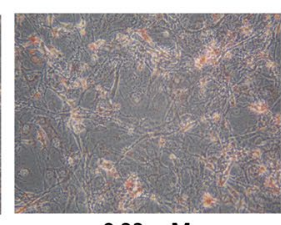

$0.33 \mathrm{mM}$

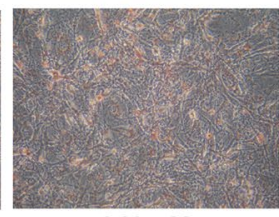

$3.30 \mathrm{mM}$

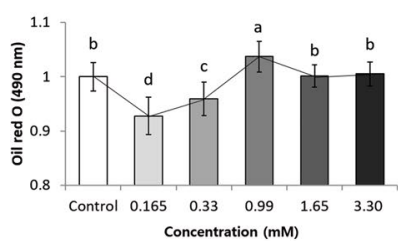

B.
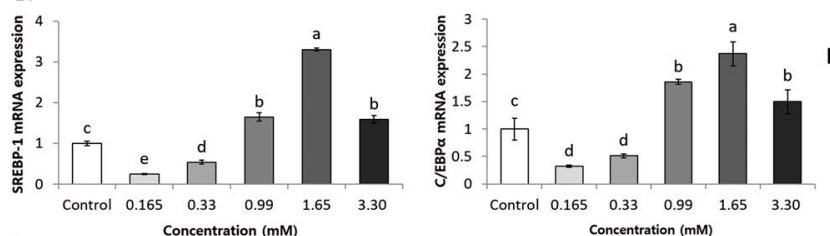

D.

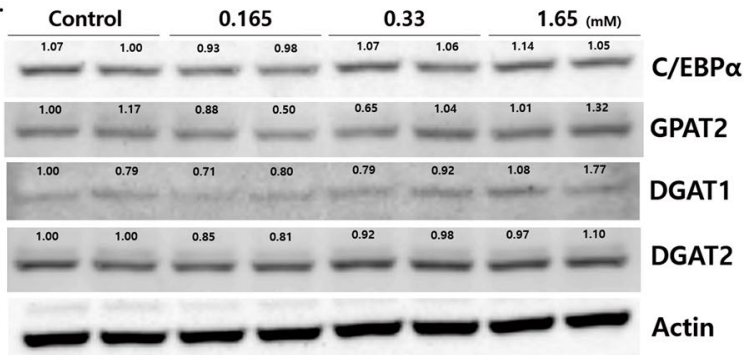

C.
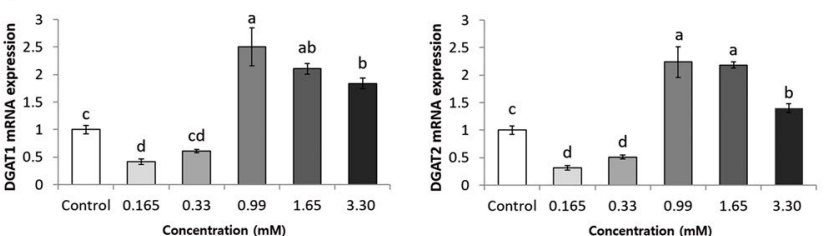

$\begin{array}{cc}0.33 & 0.99 \\ \text { Concentration }(m M) & \end{array}$

Figure 8. Appropriate concentrations of $\mathrm{MgCl}_{2}$ reduces lipid droplet accumulation and adipo/lipogenesis related gene expression in differentiated 3T3-L1 adipocytes. (A) Microscopic observation and optical density (OD, $490 \mathrm{~nm}$ ) of different concentrations of $\mathrm{MgCl}_{2}$ treated 3T3-L1 cells. (B) mRNA expression of adipo/ lipogenesis related genes of transcription factors. (C) mRNA expression of triglyceride storage (lipogenesis) related genes. (D) Protein expression of adipo/lipogenesis related genes. ${ }^{\mathrm{a}-\mathrm{c}}$ Means with different letters are significantly different $(P<0.05)$ by Duncan's multiple range test. Gene expression/Actin $\times$ Control numerical value (Control fold ratio $=1$ ) used ImageJ program. The grouping of blots cropped from different blots.

that the $\mathrm{Cl}^{-}$content in CNS was 13 times higher than $\mathrm{SO}_{4}{ }^{2-}$ (Fig. 4B). Different concentrations of $\mathrm{MgCl}_{2}$ based on the sea salt $\mathrm{Mg}$ contents were selected considering that the aim was to evaluate the effects of $\mathrm{Mg}^{2+}$ on regulating obesity with the $\mathrm{Cl}^{-}$content being a default.

In this study, 3T3-L1 adipocytes were exposed to various concentrations of $\mathrm{MgCl}_{2}$. We observed that $0.165 \mathrm{mM}$ and $0.33 \mathrm{mM} \mathrm{MgCl}_{2}$ significantly decreased lipid droplets in 3T3-L1 adipocytes (Supplement Fig. 7). As shown in Fig. 8A, $0.165 \mathrm{mM}$ markedly reduced the lipid droplets, accumulated lipid, and Oil red $\mathrm{O}$ stained lipids considerably. Furthermore, exposure to $0.165 \mathrm{mM}$ resulted in significantly reduced the mRNA expression levels of adipo/lipogenesis related transcription factors SREBP-1 (0.25 \pm 0.02$), \mathrm{C} / \mathrm{EBP} \alpha(0.32 \pm 0.02)$, and LXR $\alpha$ $(0.59 \pm 0.08)$ as compared to the Control (fold ratio: 1$)(P<0.05)$ (Fig. $8 \mathrm{~B})$. However, $0.99 \mathrm{mM}, 1.65 \mathrm{mM}$, and $3.30 \mathrm{mM}$ significantly increased the mRNA expression levels of SREBP-1 and C/EBP $\alpha$, as compared to Control. Exposure to $0.165 \mathrm{mM}$ also resulted in significant decrease in the lipogenesis related genes of mRNA expression levels of DGAT1 $(0.41 \pm 0.05)$ and DGAT2 $(0.31 \pm 0.04)$, as compared to the Control (fold ratio: 1$)(P<0.05)$ (Fig. 8C), whereas $0.99 \mathrm{mM}, 1.65 \mathrm{mM}$, and $3.30 \mathrm{mM}$ tended to increase the mRNA expression levels significantly. Assessing the levels of protein expression, $0.165 \mathrm{mM}$ significantly decreased C/EBP $\alpha$, GPAT2, DGAT1, and DGAT2, but $1.65 \mathrm{mM}$ significantly increased these genes compared to the Control $(P<0.05)$ (Fig. 8D). In addition, $0.33 \mathrm{mM}$ showed a similar tendency to $0.165 \mathrm{mM}$. Taken together, these results suggest that the appropriate $\mathrm{MgCl}_{2}$ concentrations regulate in reducing obesity, but $\mathrm{MgCl}_{2}$ concentrations beyond this optimal range induce obesity by regulating the adipo/lipogenesis related genes in 3T3-L1 adipocytes.

$\mathrm{MgCl}_{2}$ inhibits ALT enzyme activity. Results of this study reveal that CNS intake decreases the AST and ALT enzyme activity in HFD-induced obese mice serum (Fig. 4E), and $\mathrm{MgCl}_{2}$ reduces the lipid accumulation in 3T3-L1 adipocytes (Fig. 8). This study hypothesized that Mg intake will affect obesity and liver enzyme activity, and therefore examined the interaction between $\mathrm{Mg}$ and ALT enzyme activity. The $\mathrm{IC}_{50}$ values were evaluated to identify the inhibitory potential of $\mathrm{MgCl}_{2}$ and $\mathrm{NaCl}$ against ALT by performing the ALT inhibitory assay using $\mathrm{L}$-alanine as the substrate. $\mathrm{MgCl}_{2}$ was effective in inhibiting the ALT activity in a concentration-dependent manner with an $\mathrm{IC}_{50}$ value of $3.51 \pm 0.04 \mathrm{mM}$, when compared to the positive control $(0.34 \pm 0.01 \mathrm{mM})$ (Fig. $\left.9 \mathrm{~A}\right)$, but $\mathrm{NaCl}$ did not exhibit any ALT inhibitory activity. Enzyme kinetic analysis was performed to explain the mode of enzymatic inhibition with various concentrations of the corresponding substrate for ALT with the test sample 
A.

\begin{tabular}{|c|c|c|c|}
\hline Test compound & $\mathrm{IC}_{50}(\mathrm{mM})^{\mathrm{a}}$ & $K_{i}(\mathrm{mM})^{\mathrm{b}}$ & Inhibition type \\
\hline $\mathrm{MgCl}_{2}$ & $3.51 \pm 0.04$ & 1.71 & Competitive \\
\hline $\mathrm{NaCl}$ & NA & - & - \\
\hline$\beta$-chloro-L-alanine hydrochloride ${ }^{d}$ & $0.34 \pm 0.01$ & - & - \\
\hline
\end{tabular}

B.
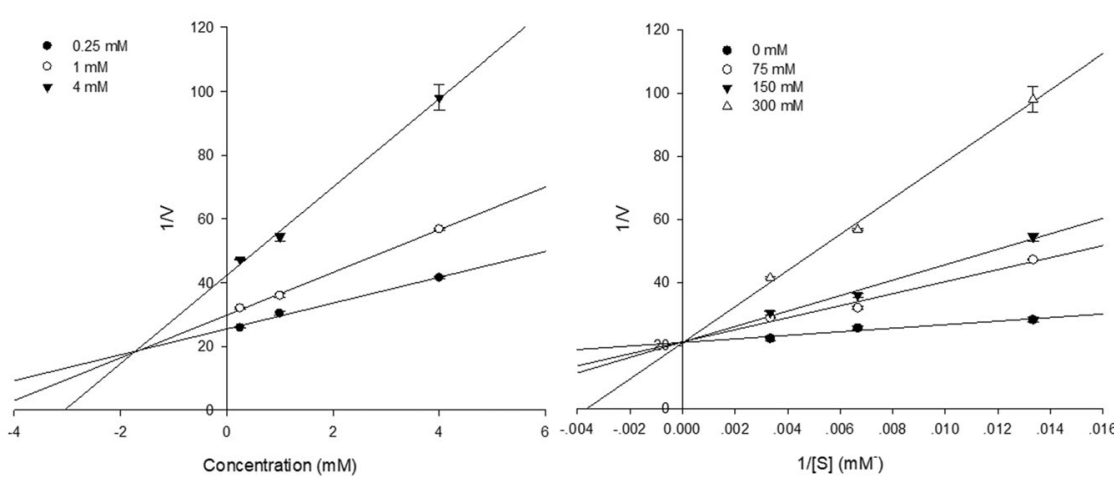

Figure 9. $\mathrm{MgCl}_{2}$ inhibits ALT enzyme activity to regulate competitive substrate and enzyme linkage. (A) aTest concentrations of these compounds were in the range of $0.125-4 \mathrm{mM}$, dissolved in ALT assay buffer: $50 \%$ inhibition concentrations $\left(\mathrm{IC}_{50}, \mathrm{mM}\right)$ are expressed as the mean \pm S.D. of triple experiments. ${ }^{\mathrm{b}}$ The inhibition constant $\left(K_{i}\right)$ was determined by interpretation of the Dixon plot. ${ }^{\mathrm{c}}$ Determined by interpretation of the Lineweaver-Burk plot. ${ }^{\mathrm{d}}$ Used as positive control in assay. NA: no activity. (B) Dixon and Lineweaver-Burk plots of the inhibition of ALT by $\mathrm{MgCl}_{2}$. The result presented demonstrates the effects of the presence of different concentrations of the substrate for $\mathrm{MgCl}_{2}$, and the effects of the presence of different concentrations of $\mathrm{MgCl}_{2}$.

$\left(\mathrm{MgCl}_{2}\right)$. As shown in Fig. 9B, increasing the concentration of the substrate intersects the $y$-axis in the Dixon plot, indicating that $\mathrm{MgCl}_{2}$ competes with the substrate to bind to the active site of the ALT enzyme with a low $K_{i}$ value of $1.71 \mathrm{mM}$, suggesting that $\mathrm{MgCl}_{2}$ has significant ALT inhibitory activity.

\section{Discussion}

Many countries have recently recommended reduced salt consumption for improving human health. However, most research has focused on reducing the level of salt consumption. On the other hand, there has been little research on the $\mathrm{NaCl}$ salt type and diseases. Therefore, this study focused on the obesity regulation between SS containing various minerals and table salt.

Generally manufactured SS (GS) is a mixture of old and new seawater used during the process of evaporation in natural sunlight and wind, whereas CNS production uses only new seawater and has reported better health benefits compared to purified salt $(\mathrm{NaCl})$ and other kinds of $\mathrm{SS}^{6,7}$. Compared to GS and FS, CNS reduces the mouse body weight, as well as size, weight, and number of lipid droplets in the epididymal fat tissues, and also inhibits expressions of the adipo/lipogenesis-related genes in A/D + HFD induced colorectal cancer and obesity mice model. This indicates the differing characteristics of SS according to the methods of processing, thereby exerting different health benefits. Since the A/D + HFD model is a dual disease-induced mouse model, mouse body weight loss and reduction of obesity-related gene expression cannot be attributed directly to sea salt or A/D treatment. This study therefore investigated the obesity-related factors in 3T3-L1 adipocytes.

LXR $\alpha$ activates transcription factors, and specifically plays a general role in lipid metabolism ${ }^{31}$. SREBP- $1^{32}$ and $\mathrm{C} / \mathrm{EBP}^{33}$ induced by LXR $\alpha$ activates acetyl-CoA carboxylase (ACC), FAS, and stearoyl-CoA desaturase 1 (SCD-1); these genes subsequently regulate accumulation of fatty acids and $\mathrm{TG}^{34}$. The enzyme LPL regulates energy balance and body weight as well as catalyzes hydrolysis of TG, lipoproteins, chylomicrons, and very low-density lipoprotein $(V L D L)^{35}$. CNS reduces the expressions of LXR, C/EBP $\alpha$, and SREBP-1. Since LXR regulates various genes related to cholesterol and fatty acid metabolism in the liver ${ }^{31}$, inhibition of 3T3-L1 lipid accumulation can be attributed to the regulation of genes associated with adipo/lipogenesis. In this study, only CNS treatment reduced the number and size of lipid droplets in fat tissue and 3T3-L1 adipocytes, as well as inhibited adipo/lipogenesis related gene expression, when compared to GS. However, although the anti-obesity effects of CNS were confirmed, there was no comparative study between $\mathrm{CNS}$ and $\mathrm{NaCl}$. Thus, $\mathrm{NaCl}$ and $\mathrm{CNS}$ were given at the same concentrations, and compared and confirmed in the next experiment.

Many studies have reported that salt intake is strongly related to obesity in humans ${ }^{36,37}$ and mice ${ }^{38}$. In this study, $1 \% \mathrm{NaCl}$ intake increased the mouse body weight, but CNS intake decreased the same, and these results are similar to our previous studies. This has been clarified in other experiments using $1 \%$ concentrated $\mathrm{NaCl}$ or SS intake ${ }^{6,7}$, and this concentration did not affect the blood sodium concentration in mice (Supplement Fig. 4A). 
Moreover, the mice were treated with $1 \%$ salts for 17 weeks, but no abnormal mouse behaviors or deaths were observed. Overall, $1 \%$ CNS intake decreased body weight of high fat induced obesity compared to $\mathrm{NaCl}$, and $1 \%$ salt intake did not have any toxicity in the 17 weeks experiment period.

Obesity parameters include percentage of fat ${ }^{39}, \mathrm{TG}, \mathrm{TC}^{40}, \mathrm{ALT}, \mathrm{AST}^{41}$, leptin ${ }^{42}$, adipogenesis (SREBP-1, C/ $\mathrm{EBP} \alpha, \mathrm{PPAR} \gamma)^{43}$, and lipogenesis related genes (SREBP-1, C/EBP $\left.\alpha, \mathrm{LXR} \alpha\right)^{44}$. Ju et al. ${ }^{7}$ reported that SS reduced the mouse body weight, epididymal white adipose tissue weight, TG, TC, and leptin in the serum of HFD-induced obese mice. Moreover, a deep seawater treatment also reduced the mouse body weight, TG, TC in $o b / o b$ mice $^{45}$. In the current study, all mice consumed the same amount of food, but the mice who ingested CNS with their high fat diet could lose weight, and improve their lipid profiles and leptin. Moreover, high fat diet induces non-alcoholic fatty liver disease (NAFLD), which refers to the accumulation of liver steatosis and is unrelated to excess alcohol consumption $^{46}$. As excessive fat develops in the liver, it damages hepatic cells, which elevates the serum levels of ALT and AST enzyme activity in the blood ${ }^{47}$. The consumption of CNS regulated the lipid profiles, leptin, and liver enzyme activity with a resulting decrease in mouse body weight. Despite the same SS, however, GS was less effective in inhibiting obesity than CNS. Therefore, although the various minerals present in SS can be attributed to the regulation of obesity, an appropriate mineral composition is very important.

Interestingly, $\mathrm{NaCl}$ intake did not significantly affect the diabetes related factors of serum glucose (Supplement Fig. 4B). Hoffmann and Cubeddu ${ }^{48}$ reported that urinary sodium is related to body weight and BMI, but not fasting glucose. Therefore, $\mathrm{NaCl}$ intake increases obesity but is inconsequential for blood glucose.

High fat diet intake induces the production of a fatty acid pool and TG accumulation in liver tissue ${ }^{49}$. CNS intake decreased the lipid accumulation and weight in liver tissue compared to the $\mathrm{NaCl}$ intake group. These results indicate that CNS intake regulates the lipid metabolism in hepatic tissue. Adipogenesis is the process that transforms pre-adipocytes into mature differentiated adipocytes ${ }^{43}$, and lipogenesis is the process of fatty acid synthesis from acetyl-CoA subunits ${ }^{44}$. In this study, CNS intake suppresses the transcription of both adipo/lipogenesis (PPAR $\gamma, \mathrm{C} / \mathrm{EBP} \alpha$, SREBP-1, and LXR $\alpha$ ) and lipogenesis related genes (FAS, GPAT2, DGAT1, 2, and LPL). In particular, FAS, being a multifunctional enzyme in the lipogenesis pathway ${ }^{4}$, was not increased by the $\mathrm{NaCl}$ intake but CNS intake decreased the levels significantly in this study. These results indicate that the anti-obesity effects of CNS is exerted by regulating adipo/lipogenesis.

The primary degradation of fatty acids is initiated by fatty acid $\beta$-oxidation in the mitochondria ${ }^{50}$, and CPT- 1 catalyzes one of the rate-limiting steps in $\beta$-oxidation ${ }^{50}$. Lipolysis of triacylglycerol stores in white adipose tissue results in the conversion of glycerol and fatty acids ${ }^{51}$, and HSL is known to hydrolyze TG, diglycerides and cholesteryl esters ${ }^{52}$. In this study, the CNS intake enhanced CPT-1 and HSL, indicating that CNS also reduces obesity by increasing the $\beta$-oxidation and lipolysis. However, $\mathrm{NaCl}$ intake decreased the expression of CPT- 1 and HSL in liver, thereby clarifying the relationship between weight gain and $\mathrm{NaCl}$ in mice. Moreover, all mice were administered $45 \%$ high fat diet or HFD + different salts diet, but the lipid concentrations in feces were similar in all groups (Supplement Fig. 5). Therefore, the anti-obesity effect of CNS is regulated by adipo/lipogenesis, $\beta$-oxidation and lipolysis, and the effects of $\mathrm{NaCl}$ on obesity are controlled specifically by $\beta$-oxidation and lipolysis in cells but are not involved in lipid excretion. One possible reason is that CNS may regulate thermogenesis in brown adipose tissue ${ }^{53}$. Unfortunately, brown adipose tissue was not examined because this study focused on finding the salts and gene regulation in hepatic and white adipose tissue. Despite this, further studies on the relationship between salt intake and thermogenesis regulation are needed. Thus far, few studies have examined the relationship between salt intake and obesity genes. Therefore, these results will form the basis for future studies of salt intake and obesity related genes.

Obesity results in an increase in the relative abundance of Firmicutes but decrease Bacteriodetes ${ }^{54}$. However, considering the relative abundance, obesity increases Actinobacteria with a significant decrease in Bacteriodetes, and no significant difference of Firmicutes ${ }^{55}$. In this study, GS intake decreased Firmicutes but CNS intake increased Firmicutes at the phylum level (Supplement Fig. 8A). Therefore, the relationship between obesity and intestinal microbiota is unclear at the phylum level, and more research will be needed on the relationship of salt intake with respect to the genus of gut microbiota. High-salt $(\mathrm{NaCl})$ diet increases Firmicutes but decreases Bacteroidetes in mice ${ }^{56}$. $\mathrm{NaCl}$ intake enhanced Firmicutes but reduced Bacteroidetes, similar to a previous study. On the other hand, CNS intake significantly increased Bacilli and Atopostipes at the genus level, which differed from the populations observed with GS intake (Supplement Fig. 8B). Hence, CNS intake affected the microbiota differently than the $\mathrm{NaCl}$ intake, and these results were attributed to the difference in mineral composition between GS and CNS

As mentioned earlier, CNS has higher $\mathrm{Na}^{+}$content than GS. However, the content ratio in GS was found to be much higher than in CNS, including $\mathrm{Mg}^{2+}$ and $\mathrm{SO}_{4} 2^{-}$. These mineralogical differences are due to manufacturing processing distinction between GS and CNS. Interestingly, the crystal structure of halite $(\mathrm{NaCl})$ mineral from the GS and CNS also reveal different patterns. Analysis of the crystal plane confirms that the control and GS have an almost identical crystal structure for halite $(\mathrm{NaCl})$, whereas the CNS shows a much higher peak at $45.54^{\circ}(1.99 \AA)$ of $(2,2,0)$ crystal plane. These results indicate that salt crystals in CNS are better developed.

A previous mineral analysis confirmed that the presence of more sulfate minerals than chloride minerals, especially $\mathrm{MgSO}_{4}$ minerals. According to the sequential precipitation of seawater analysis, since the ionic affinity between $\mathrm{Mg}^{2+}$ and $\mathrm{SO}_{4}{ }^{2-}$ is higher than $\mathrm{Cl}^{-}$, thus after the sulfate mineral is precipitated, the residual $\mathrm{Mg}^{2+}$ reacts with the $\mathrm{Cl}^{-}$and precipitates as $\mathrm{MgCl}_{2}^{24}$. However, our study samples confirm that the concentration of $\mathrm{Mg}$ did not result in the formation of chloride minerals. These differences are more evident in direct observations using SEM microscopic analysis and EDS spectroscopy approaches. Compared to aggregates of well-developed cubic structure of halite in the Control, GS was identified by the small size of halite crystals with same size of magnesium sulfate minerals, and CNS contained relatively larger size of halite crystals with no other identifiable sulfide minerals. Thus, these differences also indicate that the crystallinity of minerals is highly affected by the type of seawater. 
Numerous human studies have reported that decreasing the $\mathrm{Mg}$ intake and reduced $\mathrm{Mg}$ concentration in the serum enhances obesity and metabolic syndrome, but increasing the $\mathrm{Mg}$ intake and $\mathrm{Mg}$ concentration in serum suppresses the same ${ }^{19-25,57,58}$. In addition, within six hours, the standard concentration of $\mathrm{Mg}$ ions ranges from 40 to $80 \mathrm{mmol}$ in bowel movement ${ }^{59}$. Thus, an excess of $\mathrm{Mg}$ intake would have gastrointestinal side effects and result in magnesium toxicity. Little research has been done on the mechanisms by which $\mathrm{Mg}$ controls obesity. This study showed that CNS had better anti-obesity effects than GS, but CNS also had a lower Mg content than GS. Similar to previous results, $0.165 \mathrm{mM}$ and $0.33 \mathrm{mM}$ markedly reduced the lipid droplet, but the other concentrations produced similar effects or increased the lipid droplet compared to the Control. These concentrations were determined by reference to the magnesium content in CNS. Therefore, an appropriate $\mathrm{Mg}$ concentration would result in a subsequent decrease in obesity in 3T3-L1 adipocytes. Ford et al. ${ }^{58}$ reported that an increase in $\mathrm{Mg}$ intake reduces metabolic syndrome, but more than $466 \mathrm{mg} / \mathrm{d}$ (man) and $337 \mathrm{mg} / \mathrm{d}$ (women) $\mathrm{Mg}$ intake groups (BMI: 26.3) produced an increase in BMI compared to the $377-465 \mathrm{mg} / \mathrm{d}$ (man) and $264-366 \mathrm{mg} / \mathrm{d}$ (women) groups (BMI: 26.1). Therefore, enhancing the Mg intake reduces the obesity parameters, but ingesting more than the appropriate amount of $\mathrm{Mg}$ may increase obesity. In addition, an appropriate concentration of $\mathrm{Mg}$ reduces the lipogenesis related genes of SREBP-1, C/EBP $\alpha$, GPAT2, DGAT1, and DGAT2 in 3T3-L1 adipocytes. Based on these results, additional studies will be needed on adequate $\mathrm{Mg}$ intake in humans and the relationship between $\mathrm{Mg}$ and obesity related mechanism.

In the same population, overweight and obesity resulted in elevated serum ALT activity ${ }^{60}$. In the current study, CNS intake reduced body weight and ALT activity in mice serum. Based on our results, $\mathrm{MgCl}_{2}$ but not $\mathrm{NaCl}$ exhibited ALT inhibitory activity, indicating that the active component of these two salts is $\mathrm{Mg}$ and not $\mathrm{Cl}$ or $\mathrm{Na}$. Recent studies have reported hesperidin ${ }^{61}$, hyperoside, and $\beta$-sitosterol ${ }^{62}$ as compounds that inhibit the activity of the ALT enzyme. However, there is little research on the relationship between minerals and ALT enzymes. Our data indicates that $\mathrm{MgCl}_{2}$ binds to the active site of the ALT enzyme with a low inhibition constant $\left(K_{i}=1.71 \mathrm{mM}\right)$ and has a competitive relationship with ALT substrate (L-alanine), suggesting that it may act as a preventive or therapeutic mineral for obesity. Therefore, it is believed that SS intake regulates the ALT enzyme activity, and among the various minerals contained in the SS, Mg regulates the lipid metabolism as well as liver enzyme activity. Nevertheless, more research will be needed to reveal the relationship between minerals and liver enzymes.

In conclusion, CNS suppresses obesity by regulating the mice body weight, lipid accumulation in liver and epididymal white adipose tissue, adipo/lipogenesis, $\beta$-oxidation, lipolysis in high fat diet induced obese mice and 3T3-L1 adipocytes. CNS has a different mineral composition, crystallization, and morphology compared to $\mathrm{NaCl}$ and GS. In particular, CNS has lower Mg and S contents than GS. Moreover, an appropriate concentration of $\mathrm{MgCl}_{2}$ significantly decreased obesity in 3T3-L1 adipoctyes, as well as the ALT enzyme activity. Therefore, modification of the method of SS production alters the mineral composition, which ameliorates obesity. In addition, among the various minerals present in SS, an appropriate concentration of $\mathrm{Mg}$ is effective on the inhibition of lipid metabolism and liver enzyme activity. Thus, instead of purified salt ( $\mathrm{NaCl}$, table salt), the consumption of SS with an appropriate concentration of $\mathrm{Mg}$ can help inhibition of obesity.

\section{Methods}

Reagents and sea salts. $\mathrm{NaCl}$ (Sigma-Aldrich Co., St. Louis, $\mathrm{MO}, \mathrm{USA}$ ), $\mathrm{MgCl}_{2}$ (Sigma-Aldrich Co.), azoxymethane (A, Sigma-Aldrich Co.), isobutylmethylxanthine (Sigma-Aldrich Co.), dexamethasone (Sigma-Aldrich Co.), insulin (Welgene Inc. Gyeongsangbuk-do, Korea), and dextran sodium sulfate (D, Dextran Sulfate Sodium Salt Reagent grade, M.W. 36,000-50,000, MP Biomedicals, LLC, France) were purchased. Various sea salts (GS, FS, CNS) were prepared by Shin-il Saltern Corporation (Shinan, Jeollanam-do, Korea). More details of the manufacturing methods of sea salts are provided in the supplement methods.

Animal studies. Male mice (C57BL/6, six-weeks-old) were purchased from Orient Bio (Sungnam, Gyunggi-do, South Korea). The mice were housed in a specific pathogen-free (SPF) room (Cha Bio complex, Sungnam-si, Gyunggi-do, South Korea) and given access to a diet (DooYeol Biotech, Seoul, South Korea) and water ad libitum. The diet consisted of AIN-93G (Normal), 45\% high fat diet (HFD) or HFD containing $1 \%$ of the respective $\mathrm{NaCl}$ and sea salt samples (Supplement Table 1). This study of the mice was used in accordance with the guidelines of the Cha Laboratory Animal Research Center, and the protocol was approved by the Institutional Animal Care and Use Committee in Cha University (IACUC-160057 and IACUC-170007). More detailed information is provided in the supplement methods.

Histological observation and immunohistochemistry. Samples of the distal colon, liver, and epididymal fat from each animal underwent a histological examination and immunohistochemical examination. These organs were fixed in $10 \%(\mathrm{v} / \mathrm{v})$ neutral-buffered formalin, dehydrated in ethanol, and embedded in paraffin. The sections were sliced to a 5- $\mu \mathrm{m}$ thickness for each sample. Hematoxylin and eosin (H\&E) staining and immunohistochemistry were performed using the standard protocol and used CD56 antibody (M7304, DAKO, Carpinteria, CA, USA), HRP-conjugated monoclonal secondary goat anti-mouse IgG (K4006, DAKO) and a horseradish peroxidase-diaminobenzidine (HRP-DAB) staining kit (SK-4100, VECTOR Lab., Burlingame, CA, USA). More detail information is provided in the supplement methods.

Serum lipid, leptin, and liver enzyme profiles analysis. Triglyceride (TG) and total cholesterol (TC) levels were measured using the respective commercially available assay kits (ASAN Pharmaceutical., Seoul, Korea). Low density lipoprotein cholesterol (LDL) was calculated using the Friedewald Equation ${ }^{63}$. Leptin was measured using an assay kit (BD Science, Franklin Lakes, NJ, USA), and aspartate transaminase (AST) and 
alanine transaminase (ALT) levels were checked using their respective assay kits (ASAN Pharmaceutical.). All procedures were performed according to the manufacturer's suggested protocols.

3T3-L1 adipocytes differentiation and lipid droplet analysis. The 3T3-L1 adipocytes were purchased from the Korean Cell Line Bank (Seoul, Korea). Differentiated adipocytes were converted using isobutylmethylxanthine, dexamethasone, and insulin. Oil red $\mathrm{O}$ staining was used for lipid droplet analysis. More detail information is provided in the supplement methods.

Reverse transcription polymerase chain reaction (RT-PCR) and real-time quantitative PCR (RT-qPCR) assay. The mRNA expression levels of cancer and obesity related genes in colon, liver, and epididymal tissues from mice as well as 3T3-L1 adipocytes were measured by RT-PCR and RT-qPCR assay. RNA was extracted using Trizol reagent (Invitrogen, Carlsbad, CA, USA). cDNA was obtained using oligo dT 18 (Invitrogen), reverse transcriptase buffer (Invitrogen), dNTPs (Invitrogen), reverse transcriptase (Invitrogen), and RNase inhibitor (Invitrogen). RT-PCR was then carried out using an automatic thermocycler. Glyceraldehyde3-phosphate dehydrogenase (GAPDH) was used as a housekeeping gene. Gene expression was quantified using ImageJ software (http://rsbweb.nih.gov/ij/). In RT-qPCR, the prepared cDNA was amplified by incorporating each primer, SYBR green (Solis biodyne, Tartu, Estonia) and cDNA using a thermal cycler BioRad CFX-96 real time system. 18s rRNA was used as a housekeeping gene. All gene primer sequences are presented in Supplement Table 2. More details are provided in the supplement methods.

Western blotting. Protein was isolated from the liver, epididymal white adipose tissue, and 3T3-L1 cells using RIPA buffer (Invitrogen). Loading was performed using the mini-protein TGXgel (Bio-rad), and transfer was carried out using the iBlot ${ }^{\mathrm{TM}}$ gel transfer system and gel transfer stack PVDF (Invitrogen). The membranes were then captured using the primary antibodies. After washing, the membranes were then captured using the respective secondary antibody. After washing, ECL (Invitrogen) was treated and detected using the LAS-4000 (GE Healthcare Bio-Sciences AB, Björkgatan, Uppsala, Sweden). Gene expression was quantified using ImageJ software. Membranes were then captured using the primary antibodies SREBP-1 (sc-365513, Lot\# D1513), C/EBP $\alpha$ (sc-365318, Lot\# H0613), FAS (sc-1024, Lot\# G0312), GPAT2 (sc-168448, Lot\# A1811), DGAT1 (sc-26173, Lot\# C2315), DGAT2 (sc-66859, Lot\# A1215), CPT-1 (sc-139482, Lot\# H2213), Actin (sc-8432, Lot\# C3017) (Santa Cruz Biotechnology Inc., Dallas, TX, USA), and the respective secondary antibody (Santa Cruz Biotechnology Inc.). More detail information is provided in the supplement methods.

\section{Characteristics of Sea Salts}

Inductively coupled plasma optical emission spectrometry (ICP-OES). The metal cation mineral contents of solar salts were analyzed by ICP-OES (Optima 8300, PerkinElmer, Waltham, MA, USA) under the following conditions: operating power, $1.5 \mathrm{~kW}$; Nebulizer, mira mist, plasma gas flow, $12.0 \mathrm{~L} / \mathrm{min}$; auxiliary gas flow, $0.2 \mathrm{~L} / \mathrm{min}$; nebulizer gas flow, $0.55 \mathrm{~L} / \mathrm{min}$. The detection limit for the cations was determined to be $10 \mathrm{ppb}$.

Ion chromatography. Dissolved samples ( $\mathrm{NaCl}, \mathrm{GS}$, and $\mathrm{CNS}$ ) were analyzed by ion chromatography (IC, Dionex ICS-5000+ Reagent-Free HPIC System, Thermo Inc., USA) for anion analysis (including chloride and sulfate), which have a detection limit of $1 \mathrm{ppm}$ for $\mathrm{Cl}^{-}$and $\mathrm{SO}_{4} 2^{-}$.

X-ray diffractometer (XRD). XRD was performed on air-dried samples ( $\mathrm{NaCl}$ of control, GS, and CNS) at Yonsei University using an Ultima IV (Rigaku, Japan) model automated X-ray diffractometer with $\mathrm{Cu}-\mathrm{K} \alpha$ radiation. Oriented powder mount samples were placed on the holder. XRD profiles, over ranges of $2 \theta$ degrees, ranging from $3^{\circ}$ to $100^{\circ}$, were recorded at scan speeds of $1.5^{\circ} / \mathrm{min}$ and step sizes of $0.02^{\circ}$ with a receiving slit size of $0.3 \mathrm{~mm}$ and a divergence slit size of $1.25^{\circ}$. Crystallographica Search-Match software (v.2.0.3.1) was used to identify the composition of minerals constituting each solar salt sample.

Scanning electron microscopy (SEM). The inherent mineral morphology and texture were observed on secondary electron images (SEI) using field emission SEM (JEOL-7610F-Plus, JEOL, Japan) equipped with EDS operating at $15 \mathrm{KeV}$ with a working distance of $8 \mathrm{~mm}$; these experiments were performed at Yonsei University. Briefly, fine grains of all three samples (GS, CNS, and Control) were placed on a carbon tape and coated with platinum.

ALT enzyme activity and enzyme kinetic analysis. The ALT activity inhibitory effect of $\mathrm{MgCl}_{2}$ (Sigma) and $\mathrm{NaCl}$ (Sigma) was carried out using the alanine transaminase colorimetric activity assay kit (Cayman Chemical, Ann Arbor, MI, USA) according to the manufacture's instruction with the selected modifications. Kinetic models, Dixon plot, and Lineweaver-Burk plot were used to determine the mechanism of ALT inhibition. More detail information is provided in the supplement methods.

Statistical analysis. Data are presented as the mean \pm standard deviation (SD), and RT-qPCR data are presented as the mean \pm standard error (SE). Differences between the mean values for individual groups were assessed using one-way analysis of variance (ANOVA) of Duncan's multiple range tests. Differences were considered significant when $P<0.05$. The SPSS v18 statistical software package (SPSS Inc. Westlands, Hong Kong) was used to check these analyses.

Data availability

All data generated or analyzed during this study are included in this published article (and its Supplementary Information Files). 
Received: 25 September 2019; Accepted: 7 February 2020;

Published online: 25 February 2020

\section{References}

1. Best, J. U.S. Patent No. 3,779,030. Washington, DC: U.S. Patent and Trademark Office (1973).

2. Kim, K. M. \& Kim, I. C. The physical and chemical properties of salt manufactured by new process with brine produced in Korean salt-farms. J. Korean Soc. Food Sci. Nutr. 42, 1664-1672 (2013).

3. Ha, J. O. \& Park, K. Y. Comparison of mineral contents and external structure of various salts. J. Korean Soc. Food Sci. Nutr. 27, 413-418 (1998).

4. Zhao, X., Kim, S. H., Qi, Y., Kim, S. Y. \& Park, K. Y. Effects of different kinds of salt in the comutagenicity and growth of cancer cells. J. Korean Soc. Food Sci. Nutr. 41, 26-32 (2012).

5. Jung, K. O., Lee, K. Y., Rhee, S. K. \& Park, K. Y. Effects of various kinds of salt on the tumor formation, NK cell activity and lipid peroxidation in Sarcoma-180 cell transplanted mice. J. Korean Asso. Cancer Prev. 7, 134-142 (2002).

6. Ju, J., Kim, Y. J., Park, E. S. \& Park, K. Y. Korean solar salt ameliorates colon carcinogenesis in an A/D-induced C57BL/6 mouse model. Prev. Nutr. Food Sci. 22, 149-155 (2017).

7. Ju, J., Song, J. L., Park, E. S., Do, M. S. \& Park, K. Y. Korean solar salts reduce obesity and alter its related markers in diet-induced obese mice. Nutr. Res. Pract. 10, 629-634 (2016).

8. Jin, Y. X., Kim, H. R. \& Kim, S. Y. Effect of mineral-rich salt intake on diabetic Goto-Kakizaki Rats. J. Korean Soc. Food Sci. Nutr. 43, 355-359 (2014).

9. Chanmuang, S. et al. Effects of mineral-rich solar salt on blood pressure and insulin action in Dahl Salt-sensitive rats. 15th World Congress of Food Science and Technology, Cape Town, South Africa (Vol. 2) (2010).

10. Kim, M. J., An, H. L., Heo, S. J. \& Lee, K. S. Quality characteristics of bread with the addition of various kinds of solar salt. Culinary Sci. Hospitality Res. 17, 191-203 (2011).

11. Lanaspa, M. A. et al. High salt intake causes leptin resistance and obesity in mice by stimulating endogenous fructose production and metabolism. Proc. Nat. Acad. Sci. 115, 3138-3143 (2018).

12. Brown, I. J., Tzoulaki, I., Candeias, V. \& Elliott, P. Salt intakes around the world: implications for public health. Int. J. Epidemiol. 38, 791-813 (2009).

13. Abarca-Gómez, L. et al. Worldwide trends in body-mass index, underweight, overweight, and obesity from 1975 to 2016 : a pooled analysis of 2416 population-based measurement studies in 128. 9 million children, adolescents, and adults. Lancet 390, 2627-2642 (2017).

14. Grimes, C. A., Riddell, L. J., Campbell, K. J. \& Nowson, C. A. Dietary salt intake, sugar-sweetened beverage consumption, and obesity risk. Pediatrics 131, 14-21 (2013).

15. Lydon, R., McAnena, L., Livingstone, M. B. E. \& Kerr, M. A. The association between salt intake and obesity in UK adults aged 19-64 years. Proceeding Nutr. Soc. 75, OCE3 (2016).

16. Jackson, S. L., King, S. M., Zhao, L. \& Cogswell, M. E. Prevalence of excess sodium intake in the United States-NHANES, 2009-2012. MMWR Morb. Mortal. Wkly. Rep. 64, 1393-1397 (2016).

17. Park, E. S., Lee, S. M. \& Park, K. Y. In vitro anti-obesity effects of kimchi prepared with solar salts without bittern on 3T3-L1 adipocytes. J. Korean Soc. Food Sci. Nutr. 42, 229-234 (2018).

18. Institute of medicine (US) standing committee on the scientific evaluation of dietary reference intakes. Dietary reference intakes for calcium, phosphorus, magnesium, vitamin D, and fluoride. Washington, DC: National Academies Press, (1997).

19. King, D. E., Mainous, A. G. III, Geesey, M. E. \& Woolson, R. F. Dietary magnesium and C-reactive protein levels. J. Am. Coll. Nutr. 24, 166-171 (2005)

20. Corica, F., Allegra, A., Ientile, R. \& Buemi, M. Magnesium concentrations in plasma, erythrocytes, and platelets in hypertensive and normotensive obese patients. Am. J. Hypertens. 10, 1311-1313 (1997).

21. Huerta, M. G. et al. Magnesium deficiency is associated with insulin resistance in obese children. Diabetes Care 28, 1175-1181 (2005).

22. Jose, B. et al. Serum magnesium in overweight children. Indian Pediatr. 49, 109-112 (2012).

23. Ul Hassan, S. A. et al. Comparison of serum magnesium levels in overweight and obese children and normal weight children. Cureus 9, e1607 (2017).

24. Song, Y. et al. Dietary magnesium intake and risk of incident hypertension among middle-aged and older US women in a 10-year follow-up study. Am. J. Cardiol. 98, 1616-1621 (2006).

25. Kurpad, A. V. \& Aeberli, I. Low serum magnesium and obesity-causal role or diet biomarker. Indian Pediatr. 49, 100-101 (2012).

26. Park, K. Y., Kwon, D. Y., Lee, K. W. \& Park, S. M. (Eds.). Korean Functional Foods: Composition, Processing and Health Benefits: Chapter 14. Beneficial effects of cheonilyeom (a mineral-rich solar sea salt produced in Korea) in health and fermentation. CRC Press Boca raton. p.341-357 (2018).

27. Kubota, N. et al. PPAR $\gamma$ mediates high-fat diet-induced adipocyte hypertrophy and insulin resistance. Mol. Cell 4, 597-609 (1999).

28. Moore, D. M. \& Reynolds, R. C. X-ray Diffraction and the Identification and Analysis of Clay Minerals (Vol. 322, p. 321). Oxford: Oxford University Press. (1989).

29. Warren, J. K. Evaporites through time: Tectonic, climatic and eustatic controls in marine and nonmarine deposits. Earth-Sci. Rev. 98, 217-268 (2010).

30. Weiner, E. R. Applications of environmental aquatic chemistry. CRC press Boca Raton USA. p. $403-425$ (2007).

31. Ulven, S. M., Dalen, K. T., Gustafsson, J. A. \& Nebb, H. I. LXR is crucial in lipid metabolism. Prostaglandins Leukotrienes Essential Fatty Acid 73, 59-63 (2005)

32. Eberle, D., Hegarty, B., Bossard, P., Ferré, P. \& Foufelle, F. SREBP transcription factors: master regulators of lipid homeostasis. Biochimie 86, 839-848 (2004).

33. Steffensen, K. R. et al. Different regulation of the LXR $\alpha$ promoter activity by isoforms of CCAAT/enhancer-binding proteins. Biochem. Biophysical. Res. Commun. 293, 1333-1340 (2002).

34. Baranowski, M. Biological role of liver X receptors. J. Physiol. Pharmacol. 59, 31-55 (2008)

35. Wang, H. \& Eckel, R. H. Lipoprotein lipase: from gene to obesity. Am. J. Physiol. Endocrinol. Metabol. 297, E271-E288 (2009)

36. Hoffmann, I. S. \& Cubeddu, L. X. Salt and the metabolic syndrome. Nutr. Metabol. Cardio. Dis. 19, 123-128 (2009).

37. Grimes, C. A., Bolhuis, D. P., He, F. J. \& Nowson, C. A. Dietary sodium intake and overweight and obesity in children and adults: a protocol for a systematic review and meta-analysis. Syst. Rev. 5, 7 (2016).

38. Lanaspa, M. A. et al. High salt intake causes leptin resistance and obesity in mice by stimulating endogenous fructose production and metabolism. Proc. Nat. Acad. Sci. 115, 3138-3143 (2018).

39. Burgos, M. S. et al. Obesity parameters as predictors of early development of cardiometabolic risk factors. Ciencia Saude Coletiva 20, 2381-2388 (2015).

40. Ma, J. et al. Assessment of triglyceride and cholesterol in overweight people based on multiple linear regression and artificial intelligence model. Lipid Health Dis. 16, 42 (2017).

41. Marchesini, G., Moscatiello, S., Di Domizio, S. \& Forlani, G. Obesity-associated liver disease. J. Clin. Endocrinol. Met. 93(11_ supplement_1), s74-s80(2008). 
42. Ahima, R. S. Revisiting leptin's role in obesity and weight loss. J. Clin. Invest. 118, 2380-2383 (2008).

43. Sarjeant, K. \& Stephens, J. M. Adipogenesis. Cold Spring Harbor Perspective Biol. 4, a008417 (2012).

44. Sanders, F. W. \& Griffin, J. L. De novo lipogenesis in the liver in health and disease: more than just a shunting yard for glucose. Biological Rev. 91, 452-468 (2016).

45. Hwang, H. S., Kim, H. A., Lee, S. H. \& Yun, J. W. Anti-obesity and antidiabetic effects of deep seawater on ob/ob mice. Marine Biotechnol. 11, 531-539 (2009).

46. Smith, B. W. \& Adams, L. A. Non-alcoholic fatty liver disease. Critical Rev. Clin. Lab. Sci. 48, 97-113 (2011).

47. Kim, W. R., Flamm, S. L., Di Bisceglie, A. M. \& Bodenheimer, H. C. Serum activity of alanine aminotransferase (ALT) as an indicator of health and disease. Hepatol 47, 1363-1370 (2008).

48. Hoffmann, I. S. \& Cubeddu, L. X. Salt and the metabolic syndrome. Nutr. Metabol. Cardio. Dis. 19, 123-128 (2009).

49. Green, C. J. \& Hodson, L. The influence of dietary fat on liver fat accumulation. Nutrients 6, 5018-5033 (2014).

50. Serra, D. et al. Mitochondrial fatty acid oxidation in obesity. Antioxidants Redox Signal. 19, 269-284 (2013).

51. Zechner, R. et al. FAT SIGNALS-lipases and lipolysis in lipid metabolism and signaling. Cell Metabol. 15, 279-291 (2012).

52. Haemmerle, G. et al. Hormone-sensitive lipase deficiency in mice causes diglyceride accumulation in adipose tissue, muscle, and testis. J. Biol.l Chem. 277, 4806-4815 (2002).

53. Nicholls, D. G. \& Locke, R. M. Thermogenic mechanisms in brown fat. Physiol. Rev. 64, 1-64 (1984).

54. Ley, R. E., Turnbaugh, P. J., Klein, S. \& Gordon, J. I. Microbial ecology: human gut microbes associated with obesity. Nature 444, 1022-1023 (2006).

55. Turnbaugh, P. J. et al. A core gut microbiome in obese and lean twins. Nature 457, 480-484 (2009).

56. Wang, C. et al. High-salt diet has a certain impact on protein digestion and gut microbiota: a sequencing and proteome combined study. Frontiers Microbiol. 8, 1838 (2017).

57. Cahill, F. et al. High dietary magnesium intake is associated with low insulin resistance in the Newfoundland population. Plos One 8, e58278 (2013).

58. Ford, E. S. et al. Intake of dietary magnesium and the prevalence of the metabolic syndrome among US adults. Obesity 15, 1139-1146 (2007).

59. Portalatin, M. \& Winstead, N. Medical management of constipation. Clin. Colon Rectal Surg. 25, 12-19 (2012).

60. Ruhl, C. E. \& Everhart, J. E. Determinants of the association of overweight with elevated serum alanine aminotransferase activity in the United States. Gastroenterol. 124, 71-79 (2003).

61. Zareei, S., Boojar, M. M. \& Amanlou, M. Inhibition of liver alanine aminotransferase and aspartate aminotransferase by hesperidin and its aglycone hesperetin: An in vitro and in silico study. Life Sci. 178, 49-55 (2017).

62. Makheswari, M. U. \& Sudarsanam, D. D. Interaction of hyperoside and $\beta$-sitosterol with alanine transaminase using molecular docking. Int. J. Pharma. Res. Rev. 2, 17-24 (2013).

63. Martin, S. S. et al. Comparison of a novel method vs the Friedewald equation for estimating low-density lipoprotein cholesterol levels from the standard lipid profile. JAMA 310, 2061-2068 (2013).

\section{Acknowledgements}

This study was supported by grant 20130290 to the Solar Salt Research Center of Mokpo, National University, from the Ministry of Oceans and Fisheries, Korea.

\section{Author contributions}

Conceptualization: E.S.P., S.M.L., K.Y.P. and S.C., Data curation: E.S.P., K.Y., K.Y.P. and T.Y. Investigation: E.S.P., K.Y.P. and T.Y. Methodology: E.S.P., K.Y.P., K.Y., T.Y. and S.C. Supervision: S.M.L. and K.Y.P. Visualization: E.S.P. Writing - original draft: E.S.P., K.Y.P., K.Y. and T.Y. Writing - review \& editing: E.S.P., S.M.L. and K.Y.P.

\section{Competing interests}

The authors declare no competing interests.

\section{Additional information}

Supplementary information is available for this paper at https://doi.org/10.1038/s41598-020-60462-z.

Correspondence and requests for materials should be addressed to S.-M.L. or K.-Y.P.

Reprints and permissions information is available at www.nature.com/reprints.

Publisher's note Springer Nature remains neutral with regard to jurisdictional claims in published maps and institutional affiliations.

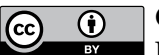

Open Access This article is licensed under a Creative Commons Attribution 4.0 International

License, which permits use, sharing, adaptation, distribution and reproduction in any medium or format, as long as you give appropriate credit to the original author(s) and the source, provide a link to the Creative Commons license, and indicate if changes were made. The images or other third party material in this article are included in the article's Creative Commons license, unless indicated otherwise in a credit line to the material. If material is not included in the article's Creative Commons license and your intended use is not permitted by statutory regulation or exceeds the permitted use, you will need to obtain permission directly from the copyright holder. To view a copy of this license, visit http://creativecommons.org/licenses/by/4.0/.

(c) The Author(s) 2020 